\title{
Intake estimation of total and individual flavan-3-ols, proanthocyanidins and theaflavins, their food sources and determinants in the European Prospective Investigation into Cancer and Nutrition (EPIC) study
}

Viktoria Knaze $^{1}$, Raul Zamora-Ros ${ }^{1 *}$, Leila Luján-Barroso ${ }^{1}$, Isabelle Romieu ${ }^{2}$, Augustin Scalbert ${ }^{2}$, Nadia Slimani $^{2}$, Elio Riboli ${ }^{3}$, Caroline T. M. van Rossum ${ }^{4}$, H. Bas Bueno-de-Mesquita ${ }^{4,5}$, Antonia Trichopoulou $^{6,7}$, Vardis Dilis ${ }^{6,7}$, Konstantinos Tsiotas ${ }^{6}$, Guri Skeie ${ }^{8}$, Dagrun Engeset ${ }^{8}$, J. Ramón Quirós9, Esther Molina ${ }^{10,11}$, José María Huerta ${ }^{11,12}$, Francesca Crowe $^{13}$, Elisabet Wirfäl ${ }^{14}$, Ulrika Ericson $^{14}$, Petra H. M. Peeters ${ }^{3,15}$, Rudolf Kaaks ${ }^{16}$, Birgit Teucher ${ }^{16}$, Gerd Johansson ${ }^{17}$, Ingegerd Johansson $^{18}$, Rosario Tumino ${ }^{19}$, Heiner Boeing ${ }^{20}$, Dagmar Drogan ${ }^{20}$, Pilar Amiano ${ }^{11,21}$, Amalia Mattiello ${ }^{22}$, Kay-Tee Khaw ${ }^{23}$, Robert Luben ${ }^{23}$, Vittorio Krogh ${ }^{24}$, Eva Ardanáz ${ }^{11,25}$, Carlotta Sacerdote $^{26}$, Simonetta Salvini ${ }^{27}$, Kim Overvad ${ }^{28}$, Anne Tjønneland ${ }^{29}$, Anja Olsen ${ }^{29}$, Marie-Christine Boutron-Ruault ${ }^{30,31}$, Guy Fagherazzi ${ }^{30,31}$, Florence Perquier ${ }^{30,31}$ and Carlos A. González ${ }^{1}$

${ }^{1}$ Unit of Nutrition, Environment and Cancer, Cancer Epidemiology Research Programme, Catalan Institute of Oncology (ICO-IDIBELL), Avda Gran Via 199-203 08907 L'Hospitalet de Llobregat, Barcelona, Spain

${ }^{2}$ Dietary Exposure Assessment Group, International Agency for Research on Cancer (IARC), Lyon, France

${ }^{3}$ Department of Epidemiology and Biostatistics, School of Public Health, Faculty of Medicine, Imperial College London, London, UK

${ }^{4}$ National Institute of Public Health and the Environment (RIVM), Bilthoven, The Netherlands

${ }^{5}$ Department of Gastroenterology and Hepatology, University Medical Center Utrecht (UMCU), Utrecht, The Netherlands

${ }^{6}$ WHO Collaborating Center for Food and Nutrition Policies, Department of Hygiene, Epidemiology and Medical Statistics,

University of Athens Medical School, Athens, Greece

${ }^{7}$ Hellenic Health Foundation, Athens, Greece

${ }^{8}$ Department of Community Medicine, University of Tromsø, Tromsø, Norway

${ }^{9}$ Public Health and Health Planning Directorate, Asturias, Spain

${ }^{10}$ Andalusian School of Public Health, Granada, Spain

${ }^{11}$ CIBER Epidemiología y Salud Pública (CIBERESP), Barcelona, Spain

${ }^{12}$ Department of Epidemiology, Murcia Regional Health Authority, Murcia, Spain

${ }^{13}$ Cancer Epidemiology Unit, Nuffield Department of Clinical Medicine, University of Oxford, Oxford, UK

${ }^{14}$ Department of Clinical Sciences in Malmö, Nutrition Epidemiology, Lund University, Malmö, Sweden

${ }^{15}$ Julius Center, University Medical Center Utrecht, Utrecht, The Netherlands

${ }^{16}$ Department of Cancer Epidemiology, German Cancer Research Center, Heidelberg, Germany

${ }^{17}$ Department of Clinical Medicine and Public Health/Nutritional Research, Umeå University, Umeå, Sweden

${ }^{18}$ Department of Odontology/Cariology, Umeå University, Umeå, Sweden

${ }^{19}$ Cancer Registry and Histopathology Unit, "Civile M.P. Arezzo" Hospital, Ragusa, Italy

${ }^{20}$ Department of Epidemiology, German Institute of Human Nutrition Potsdam-Rebbrücke, Nuthetal, Germany

${ }^{21}$ Public Health Division of Gipuzkoa, Institute Investigation BioDonostia, Basque Government, San Sebastian, Spain

${ }^{22}$ Department of Clinical and Experimental Medicine, Federico II University, Naples, Italy

${ }^{23}$ School of Clinical Medicine, University of Cambridge, Cambridge, UK

${ }^{24}$ Nutritional Epidemiology Unit, Fondazione IRCCS Istituto Nazionale dei Tumori, Milan, Italy

${ }^{25}$ Navarre Public Health Institute, Pamplona, Spain

${ }^{26}$ Center for Cancer Prevention (CPO-Piemonte), and Human Genetic Foundation (HuGeF), Torino, Italy

${ }^{27}$ Molecular and Nutritional Epidemiology Unit, ISPO Cancer Prevention and Research Institute, Florence, Italy

Abbreviations: 24-HDR, $24 \mathrm{~h}$ dietary recall; EPIC, European Prospective Investigation into Cancer and Nutrition; FCDB, food composition database; MED, Mediterranean; PA, proanthocyanidins; USDA, US Department of Agriculture.

* Corresponding author: R. Zamora-Ros, fax +34 932607787, email rzamora@iconcologia.net 
${ }^{28}$ Department of Epidemiology, School of Public Health, Aarhus University, Aarhus, Denmark

${ }^{29}$ Institute of Cancer Epidemiology, Danish Cancer Society, Copenhagen, Denmark

${ }^{30}$ INSERM, Centre for Research in Epidemiology and Population Health, U1018, Institut Gustave Roussy, F-94805 Villejuif, France

${ }^{31}$ Paris South University, UMRS 1018, F-94805 Villejuif, France

(Submitted 27 July 2011 - Final revision received 13 October 2011 - Accepted 22 October 2011 - First published online 20 December 2011)

\section{Abstract}

Epidemiological studies suggest health-protective effects of flavan-3-ols and their derived compounds on chronic diseases. The present study aimed to estimate dietary flavan-3-ol, proanthocyanidin (PA) and theaflavin intakes, their food sources and potential determinants in the European Prospective Investigation into Cancer and Nutrition (EPIC) calibration cohort. Dietary data were collected using a standardised $24 \mathrm{~h}$ dietary recall software administered to 36037 subjects aged 35-74 years. Dietary data were linked with a flavanoid food composition database compiled from the latest US Department of Agriculture and Phenol-Explorer databases and expanded to include recipes, estimations and retention factors. Total flavan-3-ol intake was the highest in UK Health-conscious men (453.6 mg/d) and women of UK General population $(377.6 \mathrm{mg} / \mathrm{d}$ ), while the intake was the lowest in Greece (men: $160 \cdot 5 \mathrm{mg} / \mathrm{d}$; women: $124 \cdot 8 \mathrm{mg} / \mathrm{d}$ ). Monomer intake was the highest in UK General population (men: $213.5 \mathrm{mg} / \mathrm{d}$; women: $178.6 \mathrm{mg} / \mathrm{d}$ ) and the lowest in Greece (men: $26.6 \mathrm{mg} / \mathrm{d}$ in men; women: $20.7 \mathrm{mg} / \mathrm{d}$ ). Theaflavin intake was the highest in UK General population (men: $29.3 \mathrm{mg} / \mathrm{d}$; women: $25.3 \mathrm{mg} / \mathrm{d}$ ) and close to zero in Greece and Spain. PA intake was the highest in Asturias (men: $455.2 \mathrm{mg} / \mathrm{d}$ ) and San Sebastian (women: $253 \mathrm{mg} / \mathrm{d}$ ), while being the lowest in Greece (men: $134.6 \mathrm{mg} / \mathrm{d}$; women: $101.0 \mathrm{mg} / \mathrm{d}$ ). Except for the UK, non-citrus fruits (apples/ pears) were the highest contributors to the total flavan-3-ol intake. Tea was the main contributor of total flavan-3-ols in the UK. Flavan-3-ol, PA and theaflavin intakes were significantly different among all assessed groups. This study showed heterogeneity in flavan-3-ol, PA and theaflavin intake throughout the EPIC countries.

\section{Key words: Flavan-3-ols: Proanthocyanidins: Theaflavins: Intake: European Prospective Investigation into Cancer and Nutrition-Europe}

Flavan-3-ols or flavanols, terms used interchangeably, are compounds that belong to a polyphenol subclass called flavonoids, which share a common C6-C3-C6 skeleton. Flavan-3-ols are perhaps the most structurally complex in the flavonoid subclass ranging from simple monomers (such as catechin and its isomer epicatechin) to oligomers (from dimers to decamers), polymers ( $>10$ mers) and other derived compounds (e.g. theaflavins and thearubigins). The oligo and polymers of flavan-3-ols are also referred to as condensed tannins or proanthocyanidins (PA), named for their ability to yield anthocyanidins when heated in acidic media ${ }^{(1)}$. Enzymatic and non-enzymatic oxidation of (gallo)catechins, reactions characteristic of green tea fermentation, results in flavanol-derived compounds: theaflavins and high-molecularweight thearubigins ${ }^{(1,2)}$. Being much larger molecules, PA and flavanol-derived compounds tend to be less bioavailable and have different functional properties; therefore they are often considered as separate groups of flavonoids ${ }^{(1,3)}$. Although their average degree of polymerisation can be estimated, the structures of some high-molecular weight polymers of PA and of most of the thearubigins have not been well defined due to inadequate analytical methods ${ }^{(1)}$.

Flavan-3-ol monomers are found ubiquitously in plants as secondary metabolites ${ }^{(4)}$. Flavan-3-ol monomers are most abundant in fruits (e.g. berries, apples/pears, stone fruits), barley, cocoa beans, nuts ${ }^{(5)}$ and their derived products ${ }^{(6)}$. Gallocatechins are found, almost exclusively, in green tea infusions ${ }^{(2,7)}$ while flavanol-derived compounds, theaflavins and thearubigins, are abundant in fermented black and oolong teas ${ }^{(2)}$. Common PA-rich foods are cocoa, berries, nuts and some raw beans ${ }^{(5,8)}$. Transformations and losses of some flavonoid compounds during processing and cooking are common and vary for different subclasses and even for the individual compounds ${ }^{(9-11)}$.

Total and individual compounds of flavan-3-ols have been studied extensively in vitro for their antioxidant, antiinflammatory, immunomodulator and anti-carcinogenic effects $^{(12-14)}$. A plethora of human intervention studies currently available strongly suggests beneficial effects on human health, particularly the effects of flavan-3-ol-rich foods, such as tea, cocoa and chocolate ${ }^{(7,15,16)}$. Intervention studies involving various PA-rich sources such as red wine, grape, pomegranate, chocolate and cranberry juice showed numerous positive effects on antioxidant, CVD and endothelial maintenance biomarkers ${ }^{(3)}$. Given the limited reported bioavailability of PA, particularly those having a high degree of polymerisation $(>3)^{(17)}$, the observed action of PA-rich foods in the body, with the exception of perhaps the intestinal lumen, may be attributed to flavan-3-ol monomers, which are systematically associated to $\mathrm{PA}$ and comprise $5-25 \%$ in these foods, or to other yet unidentified $\mathrm{PA}^{(3,18)}$. Furthermore, PA may also exert their action after their degradation by the colonic microbiota and subsequent absorption ${ }^{(19)}$. Indeed, two Italian case-control studies suggested inverse associations between PA, but not flavan-3-ol monomer, intake and gastric and colorectal cancers ${ }^{(20,21)}$. Furthermore, the inverse association augmented with increasing degrees of polymerisation of PA in colorectal cancer cases ${ }^{(20)}$ despite their observed 
decrease in absorption. Further research, particularly in prospective studies, on individual flavan-3-ol and PA compounds is clearly needed to clarify and confirm these potential effects.

Total intake of any nutrients is usually related to sex, cultural, lifestyle and socio-economic factors that may affect accessibility to and habitual consumption of health-promoting foods. Studies in European Prospective Investigation into Cancer and Nutrition (EPIC) Spain and the USA found significant differences in total flavonoid intake between sexes and among different age groups, socio-economic levels and ethnic groups ${ }^{(22,23)}$. Therefore, these factors need to be taken into consideration when looking into associations of these compounds and their dietary sources in disease prevention. To our knowledge, there are few data on individual flavan-3-ol intakes in the European population. The present study aims to evaluate total, subclasses and individual dietary intake of flavan-3-ols and their main food sources by EPIC centre and geographical region, while taking into account lifestyle, anthropometric and socio-demographic factors.

\section{Materials and methods}

\section{Study population}

EPIC is an ongoing prospective cohort study designed to investigate the associations between diet, lifestyle and cancer throughout ten Western European countries: Denmark, France, Germany, Greece, Italy, Norway, Spain, Sweden, The Netherlands and $\mathrm{UK}^{(24)}$. The cohort includes approximately 366000 women and 153000 men, most of them aged 35-74 years, who were enrolled between 1992 and 2000 by twenty-three centres. Some differences in methods of recruitment exist between centres. Part of the Oxford (UK) cohort was recruited from subjects who consumed a vegetariantype diet. This was designated a 'Health-conscious' group and shall be distinguished from the UK General population cohort which is a combined group of the UK Cambridge and UK Oxford general population. The female part of the cohort in Florence (Italy) and Utrecht (The Netherlands) is composed of women who underwent breast cancer screening. The French cohorts recruited women only, but from the members of the health insurance scheme for the state-school employees. The centres in Italy and Spain recruited mostly blood donors. For the purpose of dietary consumption patterns analysis, the initial twenty-three centres were later redefined by geographical areas into twenty-seven centres ${ }^{(25)}$. The calibration subsample of the EPIC cohort study composed of 36994 subjects ( $8 \%$ of the whole EPIC cohort), who were recruited to be a random sample stratified by age, sex and centre, and weighted for expected cancer cases in each stratum of the main EPIC cohort study, was considered herein. After exclusion of 945 subjects under 35 or over 74 years of age because of low participation in these age categories, and sixteen subjects without baseline dietary data, a total of 36037 subjects were included. Approval for the study was obtained from the ethical review boards of all local recruiting research institutions. All participants provided written informed consent.

\section{Measurements of diet and other lifestyle factors}

Dietary intake was measured with a standardised $24 \mathrm{~h}$ dietary recall (24-HDR) administered via a computerised interview programme (EPIC-SOFT) developed specifically for the EPIC calibration study ${ }^{(25,26)}$. The $24-\mathrm{HDR}$ was administered in a face-to-face interview, except in Norway where it was obtained by telephone ${ }^{(27)}$. A detailed description of the rationale and methodology of the 24-HDR calibration study in the EPIC cohort has been described elsewhere ${ }^{(24,28-30)}$. Data on socio-demographic and lifestyle factors, including educational level, physical activity and smoking history were collected at baseline through standardised questionnaires and clinical examinations for the calibration sample ${ }^{(31-34)}$. Age as well as body weight and height were self-reported by the participants during the 24-HDR interview. The mean time interval between these baseline questionnaire measures and the $24-H D R$ interview varied by country, from $1 \mathrm{~d}$ to 3 years ${ }^{(24)}$.

\section{Flavonoid Food Composition Database}

The US Department of Agriculture (USDA) released a PA database in 2004 and an updated flavonoid database in 2007, with more analytical values for raw, cooked, canned and commercially processed foods ${ }^{(35,36)}$. In the process of combining the two USDA databases, we observed data duplicity of the monomers. Since flavan-3-ols monomers (USDA database on flavonoids) ${ }^{(35)}$ and PA monomers (USDA database on PA) ${ }^{(36)}$ are the same molecules, the PA monomer data was removed. We expanded these databases with analytical values from the Phenol-Explorer database released in $2009^{(37)}$. Approximately, 6.5 and $0.6 \%$ of our database came from USDA and Phenol-Explorer, respectively. Thus far, these databases are the most complete and updated databases on flavonoids/polyphenols and they evaluate and compile the most worldwide food composition data published. We further expanded our EPIC-specific food composition database (FCDB) by estimating values for foods not present in either of the two databases, but that had occurred in the 24-HDR. Therefore, for our FCDB, we calculated estimated values (92.9\%) including logical zeros (25.3\%), estimations based on similar food items $(22.5 \%)$, application of retention factors (27.7\%) and recipes (17.3\%). When there were no analytical data provided for cooked foods by either USDA or PhenolExplorer, retention factors were applied. The retention factors reported in various foods were between 42 and $74 \%$ for catechins and 0 and $95 \%$ for tannins ${ }^{(38)}$. Therefore, to simplify and homogenise the calculations, we used the same retention factors for all flavonoids, as in our previous studies $(23,39,40)$ They were 70,35 and $25 \%$ after frying, cooking in a microwave oven and boiling, respectively ${ }^{(41)}$. The final FCDB created contained a total of 1877 food items. The unknown composition values, without any analytical or estimated data, were calculated as a zero by default and ranged from $2 \%$ (theaflavin gallates) to 16\% (epicatechin-3-gallates). Finally, the 24-HDR food items were linked with the expanded flavonoid FCDB using an ad hoc SQL (Structured Query Language) application. 


\section{Statistical methods}

General linear modelling was used for the calculation of the adjusted daily mean (least squared) intake and standard error using SPSS (version 17.0.0, SPSS, Inc.) for total flavan3 -ols, their individual compounds and subgroups. The mean intake was adjusted for age, weighted by season and day of 24-HDR and stratified by EPIC centre and age. Flavan-3-ol monomers as aglycones included: catechin, epigallocatechin, epicatechin, epicatechin-3-gallate, epigallocatechin-3-gallate, gallocatechin and catechin-3-gallate. PA were divided into the following subgroups: dimers, trimers, 4-6mers, 7-10mers and $>10$ mers (polymers). Theaflavins included compounds: theaflavin, theaflavin-3,3'-digallate, theaflavin- $3^{\prime}$ gallate and theaflavin-3-gallate. Although present in the USDA database, due to the extensive limitations in analytical methods currently employed to identify and quantify thearubigins, we did not include them in our analysis of total flavan-3ols $^{(1,41)}$. Epigallocatechin, epicatechin-3-gallate, epigallocatechin-3-gallate, gallocatechin and catechin-3-gallate were later combined into a single group called '(epi)gallocatechins' due to the resemblance among the chemical structures. Flavan-3ol monomer, PA and theaflavin intakes are calculated as the sum of the individual compounds or subgroups and expressed in $\mathrm{mg} / 100 \mathrm{~g}$ of fresh weight. During the analysis of the related factors and of the main food sources, EPIC centres were combined by geographical regions into a Mediterranean (MED) region (Greece, Italy, Spain and South of France) and non-MED (non-MED) region (France other than the South centre, Germany, The Netherlands, Norway, Denmark and Sweden). The UK General population cohort and the Health-conscious cohort presented similar intakes for flavan3-ols and their food sources but markedly different from all others; therefore, in the socio-demographic analysis they were kept as a separate UK region. The contribution of each food and food group to the total and individual intake of flavan-3-ols was calculated as a percentage. The general linear modelling was also used in the comparison of the mean intakes by socio-demographic, anthropometric and lifestyle factors, adjusting for age, region, energy intake and BMI, and weighted for season and day of 24-HDR. $P$ values $<0.05$ indicated significance.

\section{Results}

A south-to-north gradient in the daily mean intake of total and monomers of flavan-3-ols and of theaflavins was observed among EPIC centres in both men and women (Table 1). The highest total flavan-3-ol intake was observed in the UK Health-conscious men $(453.6 \mathrm{mg} / \mathrm{d})$ and in women of the UK General population cohort $(377.6 \mathrm{mg} / \mathrm{d})$. The lowest total intake was observed in Greek men $(160.5 \mathrm{mg} / \mathrm{d})$ and women $(124.8 \mathrm{mg} / \mathrm{d})$. Flavan-3-ol monomer intake was the highest in the UK General population $(213.5 \mathrm{mg} / \mathrm{d}$ in men, $178.6 \mathrm{mg} / \mathrm{d}$ in women) and the lowest in Greece $(26.6 \mathrm{mg} / \mathrm{d}$ in men, $20.7 \mathrm{mg} / \mathrm{d}$ in women). Theaflavin intake was the highest in the UK General population for both men $(29.3 \mathrm{mg} / \mathrm{d})$ and women $(25.3 \mathrm{mg} / \mathrm{d})$. Daily theaflavin intake was close to
$0 \mathrm{mg}$ in Greece and in Spanish and southern Italian centres (Ragusa, Naples and Florence). In contrast, daily intake of total PA was the highest in Spanish centres $(455.2 \mathrm{mg}$ in men from Asturias and $237.9 \mathrm{mg}$ in women from San Sebastian), followed by men in Turin (Italy) and women in Asturias (Spain), respectively. However, PA intake was the lowest in Greece $(134.6 \mathrm{mg} / \mathrm{d}$ in men and $101.0 \mathrm{mg} / \mathrm{d}$ in women). Intake amounts of the individual flavan-3-ols, theaflavins and of PA subgroups are presented in Annexes 1 and 2. PA subclass, particularly the group of polymers ( $>10$ mers), was the highest contributor to the total flavan-3-ol intake (Table 2). Flavan-3-ol monomers were the second highest contributors to the total intake, providing contribution of between $18.6 \%$ in the MED region and $44.9 \%$ in the UK. Catechins and epicatechins, equally, were the main singlecompound contributors in the MED region, while in the non-MED and UK regions it was the epigallocatechin-3-gallate monomers. Theaflavins were the lowest contributors to the total flavan-3-ol intake. The four theaflavin compounds contributed almost equally to the total theaflavins in all three regions.

Non-citrus fruit, particularly apples/pears, was the most important food source of total flavan-3-ols in the MED $(56 \cdot 2 \%)$ and non-MED (34.1\%) regions (Table 3 ). Wine and then tea were the other two major sources of flavan-3-ols in these two regions. On the other hand, tea (51.3\%) was the most prominent source of total flavan-3-ols in the UK, followed by non-citrus fruit $(19 \cdot 9 \%)$ and wine $(6 \cdot 1 \%)$. The major food sources of catechins and epicatechins in all three regions were tea, non-citrus fruits and wine; however, chocolate candy/bars were also noteworthy dietary contributors. Tea was the lone source of theaflavins and a major source of (epi)gallocatechins in all three regions $(77.7 \%$ in the MED, $90.5 \%$ in the non-MED and $95.1 \%$ in the UK region). The principal dietary source of total PA in the MED region was non-citrus fruit $(62 \cdot 3 \%)$ followed by wine $(17 \cdot 3 \%)$ and chocolate candy/bars (4.6\%). Non-citrus fruits were also the main source of PA in the non-MED and UK regions, but their contributions were smaller (48.0 and $37 \cdot 2 \%$, respectively). In the non-MED region, wine was the second most important source (12.6\%), followed by chocolate/candy (6.6\%) and tea $(5.0 \%)$. Whereas in the UK region, the secondary sources of PA were tea $(15.0 \%)$, wine $(10 \cdot 0 \%)$, cakes/pies/pastries/puddings (7.6\%) and pulses (7.1\%).

Sex-stratified analysis of the related factors showed similar results; therefore the data are presented for men and women combined (Table 4). Total flavan-3-ol intake and also the intake stratified by monomers, PA and theaflavins were shown to significantly vary between the geographical regions. The intake of flavan-3-ol monomers and theaflavins in the UK region was almost 4-fold and over 16-fold that of the MED region, respectively. Conversely, PA intake was significantly higher in the MED region $(217 \cdot 2 \mathrm{mg} / \mathrm{d})$ compared to the non-MED $(177.9 \mathrm{mg} / \mathrm{d})$ and the UK $(198.4 \mathrm{mg} / \mathrm{d})$ regions. After adjusting for BMI and energy, women had significantly higher intakes of total flavan-3-ols and their subclasses. The intake of total flavan-3-ols and their subclasses was significantly different between the age groups, being the highest 
Table 1. Adjusted ${ }^{\star}$ daily mean intakes $(\mathrm{mg} / \mathrm{d})$ of total and subgroups of flavan-3-ols in men and women by European Prospective Investigation into Cancer and Nutrition centre ordered from south to north

(Mean values with their standard errors)

\begin{tabular}{|c|c|c|c|c|c|c|c|c|c|c|c|c|c|c|c|c|c|c|}
\hline \multirow[b]{3}{*}{ Country and centre } & \multicolumn{9}{|c|}{ Men } & \multicolumn{9}{|c|}{ Women } \\
\hline & \multirow[b]{2}{*}{$n$} & \multicolumn{2}{|c|}{$\begin{array}{c}\text { Total } \\
\text { flavan-3-ols }\end{array}$} & \multicolumn{2}{|c|}{ Monomers $\dagger$} & \multicolumn{2}{|c|}{ PA } & \multicolumn{2}{|c|}{ Theaflavins $\ddagger$} & \multirow[b]{2}{*}{$n$} & \multicolumn{2}{|c|}{$\begin{array}{c}\text { Total } \\
\text { flavan-3-ols }\end{array}$} & \multicolumn{2}{|c|}{ Monomers $†$} & \multicolumn{2}{|c|}{ PA } & \multicolumn{2}{|c|}{ Theaflavins $\ddagger$} \\
\hline & & Mean & SE & Mean & SE & Mean & SE & Mean & SE & & Mean & SE & Mean & $\mathrm{SE}$ & Mean & SE & Mean & SE \\
\hline Greece & 1314 & $160 \cdot 5$ & $7 \cdot 6$ & $26 \cdot 6$ & 3.0 & 134.6 & 6.9 & 0.3 & 0.3 & 1373 & $124 \cdot 8$ & $7 \cdot 4$ & $20 \cdot 7$ & 2.9 & $101 \cdot 0$ & 6.5 & 0.6 & 0.3 \\
\hline \multicolumn{19}{|l|}{ Spain } \\
\hline Granada & 214 & 279.4 & $18 \cdot 7$ & 41.7 & $7 \cdot 3$ & 221.8 & $22 \cdot 7$ & 0.6 & 1.1 & 300 & $151 \cdot 7$ & $15 \cdot 8$ & 20.5 & $6 \cdot 2$ & $132 \cdot 3$ & $15 \cdot 4$ & 0.1 & 0.8 \\
\hline Murcia & 243 & 279.9 & 17.5 & 43.3 & 6.9 & 235.8 & $18 \cdot 9$ & 0.3 & 0.9 & 304 & $184 \cdot 2$ & $15 \cdot 7$ & 24.6 & $6 \cdot 2$ & $159 \cdot 3$ & $18 \cdot 1$ & 0.2 & 0.9 \\
\hline Navarra & 444 & $286 \cdot 2$ & $13 \cdot 0$ & $40 \cdot 1$ & $5 \cdot 1$ & $235 \cdot 2$ & $15 \cdot 5$ & 0.0 & 0.8 & 271 & $180 \cdot 6$ & $16 \cdot 6$ & $21 \cdot 1$ & 6.5 & $164 \cdot 1$ & $18 \cdot 2$ & 0.0 & 0.9 \\
\hline San Sebastian & 490 & 422.9 & $12 \cdot 4$ & $49 \cdot 1$ & 4.9 & 357.3 & $15 \cdot 5$ & 0.0 & 0.8 & 244 & $267 \cdot 8$ & 17.5 & $30 \cdot 6$ & 6.9 & 237.9 & 18.9 & 0.5 & 0.9 \\
\hline Asturias & 386 & $498 \cdot 3$ & 13.9 & 54.7 & 5.5 & $455 \cdot 2$ & 14.9 & 0.1 & 0.7 & 324 & $286 \cdot 3$ & $15 \cdot 2$ & $33 \cdot 6$ & $6 \cdot 0$ & $236 \cdot 8$ & $15 \cdot 6$ & 0.3 & 0.8 \\
\hline \multicolumn{19}{|l|}{ Italy } \\
\hline Ragusa & 168 & 317.5 & $21 \cdot 1$ & 53.9 & $8 \cdot 3$ & 239.6 & $28 \cdot 8$ & 0.4 & 1.4 & 138 & 235.4 & 23.3 & $37 \cdot 3$ & $9 \cdot 2$ & 193.7 & $27 \cdot 1$ & 0.4 & 1.4 \\
\hline Naples & & & & & & & & & & 403 & $217 \cdot 4$ & $13 \cdot 6$ & $36 \cdot 9$ & 5.4 & 204.6 & $14 \cdot 4$ & 0.4 & 0.7 \\
\hline Florence & 271 & 382.7 & $16 \cdot 6$ & $61 \cdot 1$ & 6.5 & 325.5 & 18.4 & 0.7 & 0.9 & 784 & $264 \cdot 3$ & $9 \cdot 8$ & 54.5 & 3.8 & 209.5 & 11.3 & 1.0 & 0.6 \\
\hline Turin & 676 & 435.3 & 10.5 & 73.6 & $4 \cdot 1$ & 370.8 & 11.9 & 0.6 & 0.6 & 392 & $303 \cdot 6$ & $13 \cdot 8$ & $66 \cdot 6$ & 5.4 & $228 \cdot 2$ & $19 \cdot 4$ & 1.5 & 1.0 \\
\hline Varese & 327 & 379.9 & & $77 \cdot 2$ & $5 \cdot 9$ & $258 \cdot 7$ & 23.5 & 1.4 & 1.2 & 794 & 276.4 & 9.7 & $70 \cdot 4$ & $3 \cdot 8$ & 192.4 & 9.9 & 1.7 & 0.5 \\
\hline \multicolumn{19}{|l|}{ France } \\
\hline South coast & & & & & & & & & & 620 & 251.5 & $11 \cdot 0$ & $66 \cdot 1$ & $4 \cdot 3$ & $181 \cdot 6$ & $9 \cdot 3$ & $5 \cdot 2$ & 0.5 \\
\hline South & & & & & & & & & & 1425 & $290 \cdot 7$ & $7 \cdot 2$ & $82 \cdot 6$ & $2 \cdot 8$ & 201.5 & $6 \cdot 3$ & 8.0 & 0.3 \\
\hline North-East & & & & & & & & & & 2059 & $290 \cdot 2$ & $6 \cdot 0$ & $78 \cdot 6$ & $2 \cdot 4$ & $210 \cdot 0$ & $5 \cdot 3$ & $7 \cdot 3$ & 0.3 \\
\hline North-West & & & & & & & & & & 631 & 281.4 & $10 \cdot 9$ & $83 \cdot 7$ & $4 \cdot 3$ & $185 \cdot 9$ & 9.8 & 8.8 & 0.5 \\
\hline \multicolumn{19}{|l|}{ Germany } \\
\hline Heidelberg & 1034 & 301.6 & 8.5 & $88 \cdot 3$ & $3 \cdot 3$ & 207.6 & $15 \cdot 9$ & $6 \cdot 6$ & 0.8 & 1087 & 321.9 & 8.4 & 107.5 & 3.3 & 175.9 & $21 \cdot 7$ & 4.1 & $1 \cdot 1$ \\
\hline Potsdam & 1233 & $277 \cdot 1$ & $7 \cdot 8$ & $72 \cdot 0$ & $3 \cdot 1$ & 209.7 & 8.7 & $4 \cdot 3$ & 0.4 & 1061 & 261.5 & 8.4 & $59 \cdot 9$ & $3 \cdot 3$ & $187 \cdot 8$ & $12 \cdot 2$ & $2 \cdot 9$ & 0.6 \\
\hline \multicolumn{19}{|l|}{ The Netherlands } \\
\hline Bilthoven & 1024 & 220.6 & 8.6 & $77 \cdot 8$ & 3.4 & 128.1 & $20 \cdot 8$ & $10 \cdot 4$ & 1.0 & 1086 & 233.8 & 8.4 & 85.9 & 3.3 & $118 \cdot 2$ & 20.5 & 11.4 & 1.0 \\
\hline Utrecht & & & & & & & & & & 1870 & $286 \cdot 8$ & $6 \cdot 3$ & 114.6 & 2.5 & $159 \cdot 0$ & $5 \cdot 4$ & $16 \cdot 0$ & 0.3 \\
\hline \multicolumn{19}{|l|}{ UK } \\
\hline General population & 403 & 439.6 & $13 \cdot 6$ & 213.5 & $5 \cdot 4$ & $217 \cdot 1$ & $12 \cdot 8$ & $29 \cdot 3$ & 0.6 & 571 & 377.6 & 11.4 & 178.6 & 4.5 & 172.9 & 10.5 & $25 \cdot 3$ & 0.5 \\
\hline Health-conscious & 113 & 453.6 & $25 \cdot 7$ & $156 \cdot 1$ & $10 \cdot 1$ & 277.6 & $25 \cdot 9$ & $27 \cdot 4$ & $1 \cdot 3$ & 196 & 368.9 & 19.5 & $148 \cdot 8$ & $7 \cdot 7$ & 201.4 & $19 \cdot 2$ & $21 \cdot 1$ & 1.0 \\
\hline \multicolumn{19}{|l|}{ Denmark } \\
\hline Copenhagen & 1356 & $325 \cdot 5$ & 7.4 & $96 \cdot 0$ & $2 \cdot 9$ & 229.6 & 11.2 & $9 \cdot 7$ & 0.6 & 1484 & 319.4 & $7 \cdot 1$ & $102 \cdot 1$ & $2 \cdot 8$ & 205.4 & $10 \cdot 2$ & 11.0 & 0.5 \\
\hline Aarhus & 567 & $312 \cdot 7$ & 11.5 & $85 \cdot 7$ & 4.5 & $295 \cdot 7$ & 23.7 & $5 \cdot 6$ & 1.2 & 510 & $347 \cdot 7$ & $12 \cdot 1$ & 92.5 & 4.8 & 218.5 & $22 \cdot 8$ & 8.9 & 1.1 \\
\hline Sweden & & & & & & & & & & & & & & & & & & \\
\hline Malmö & 1421 & $242 \cdot 3$ & $7 \cdot 4$ & 103.9 & $2 \cdot 9$ & $143 \cdot 7$ & 7.4 & $3 \cdot 1$ & 0.4 & 1711 & $235 \cdot 3$ & $6 \cdot 7$ & 98.9 & $2 \cdot 6$ & $140 \cdot 7$ & $5 \cdot 6$ & 3.1 & 0.3 \\
\hline Umeå & 1344 & $287 \cdot 4$ & 7.5 & $113 \cdot 9$ & 2.9 & $171 \cdot 8$ & $7 \cdot 8$ & $3 \cdot 7$ & 0.4 & 1574 & 271.3 & 6.9 & 108.9 & $2 \cdot 7$ & $160 \cdot 7$ & $6 \cdot 6$ & 3.7 & 0.3 \\
\hline Norway & & & & & & & & & & & & & & & & & & \\
\hline South and East & & & & & & & & & & 1004 & 298.9 & 8.7 & $85 \cdot 2$ & 3.4 & $218 \cdot 2$ & 8.7 & $6 \cdot 6$ & 0.4 \\
\hline North and West & & & & & & & & & & 793 & $289 \cdot 2$ & $9 \cdot 8$ & 70.5 & $3 \cdot 8$ & 232.0 & 9.9 & 4.9 & 0.5 \\
\hline
\end{tabular}

A, proanthocyanidins.

ighted by season and day of recall.

3-gallate, epigallocatechin 3-gallate, gallocatechin and catechin-3-gallate.

¥ Sum of theaflavin, theaflavin-3'-gallate, theaflavin-3 gallate and theaflavin-3,3'-digallate. 
Table 2. Percentage contribution* of individual and subclasses of flavan-3-ols to subclass and total intake in the European Prospective Investigation into Cancer and Nutrition cohort by European region

\begin{tabular}{|c|c|c|c|c|c|c|}
\hline \multirow[b]{3}{*}{ Class and compound } & \multicolumn{6}{|c|}{ Region } \\
\hline & \multicolumn{2}{|c|}{ MED countries } & \multicolumn{2}{|c|}{ Non-MED countries } & \multicolumn{2}{|c|}{ UK } \\
\hline & Class $(\%)$ & Total (\%) & Class (\%) & Total (\%) & Class $(\%)$ & Total (\%) \\
\hline Flavan-3-ol monomers & $100 \cdot 0$ & $18 \cdot 6$ & $100 \cdot 0$ & $32 \cdot 9$ & $100 \cdot 0$ & 44.9 \\
\hline$(+)$-Catechin & $30 \cdot 0$ & $5 \cdot 6$ & $17 \cdot 6$ & $5 \cdot 8$ & $12 \cdot 4$ & $5 \cdot 6$ \\
\hline (-)-Epigallocatechin & 9.4 & 1.7 & $13 \cdot 8$ & 4.5 & 17.5 & 7.9 \\
\hline (-)-Epicatechin & $30 \cdot 1$ & $5 \cdot 6$ & $17 \cdot 8$ & $5 \cdot 8$ & $12 \cdot 6$ & $5 \cdot 7$ \\
\hline (-)-Epicatechin 3-gallate & 7.4 & 1.4 & 11.9 & 3.9 & 13.6 & $6 \cdot 1$ \\
\hline (-)-Epigallocatechin 3-gallate & $17 \cdot 0$ & $3 \cdot 2$ & $26 \cdot 8$ & $8 \cdot 8$ & $21 \cdot 2$ & 9.5 \\
\hline (+)-Gallocatechin & 1.7 & 0.3 & 3.0 & 1.0 & 4.7 & $2 \cdot 1$ \\
\hline (+)-Catechin 3-gallate & $4 \cdot 3$ & 0.8 & $9 \cdot 1$ & 3.0 & $18 \cdot 1$ & $8 \cdot 1$ \\
\hline PA or condensed tannins & $100 \cdot 0$ & $80 \cdot 8$ & $100 \cdot 0$ & $64 \cdot 8$ & $100 \cdot 0$ & $48 \cdot 8$ \\
\hline PA dimers & $19 \cdot 1$ & $15 \cdot 4$ & $20 \cdot 7$ & 13.4 & 28.9 & $14 \cdot 1$ \\
\hline PA trimers & $6 \cdot 8$ & 5.5 & $7 \cdot 2$ & 4.7 & $7 \cdot 8$ & 3.8 \\
\hline PA 4-6mers & 22.5 & $18 \cdot 2$ & $20 \cdot 6$ & 13.4 & $19 \cdot 0$ & 9.2 \\
\hline PA 7-10mers & $16 \cdot 7$ & 13.5 & $15 \cdot 0$ & 9.7 & $13 \cdot 6$ & $6 \cdot 6$ \\
\hline PA polymers (>10mers) & 34.9 & $28 \cdot 2$ & $36 \cdot 4$ & 23.6 & $30 \cdot 7$ & $15 \cdot 0$ \\
\hline Theaflavins & $100 \cdot 0$ & 0.6 & $100 \cdot 0$ & $2 \cdot 4$ & $100 \cdot 0$ & 6.4 \\
\hline Theaflavin & $26 \cdot 0$ & 0.2 & $26 \cdot 0$ & 0.6 & $25 \cdot 9$ & 1.6 \\
\hline Theaflavin-3,3'-digallate & $29 \cdot 1$ & 0.2 & $29 \cdot 2$ & 0.7 & $29 \cdot 2$ & 1.9 \\
\hline Theaflavin-3'-gallate & $22 \cdot 7$ & 0.1 & $22 \cdot 6$ & 0.5 & $22 \cdot 7$ & 1.4 \\
\hline Theaflavin-3-gallate & $22 \cdot 2$ & 0.1 & $22 \cdot 2$ & 0.5 & $22 \cdot 3$ & 1.4 \\
\hline
\end{tabular}

MED, Mediterranean; Non-MED, non-Mediterranean; PA, proanthocyanidins.

*Values are percentages derived from models adjusted for sex, age and weighted by season and day of recall.

in the 55- to 64-year-olds. It also increased with the level of education completed and the level of physical activity. On the other hand, current smokers and obese participants (BMI $\geq 30 \mathrm{~kg} / \mathrm{m}^{2}$ ) had the lowest intakes of total flavan-3-ols and their subclasses.

\section{Discussion}

To our knowledge, this is the only study thus far assessing the intake of total and flavan-3-ol monomers, PA and flavan-3-olderived compounds as well as their food sources and associated factors in all twenty-seven EPIC centres of ten European countries using a common expanded flavonoid FCDB and dietary assessment method (24-HDR). Our results show a wide range of total flavan-3-ol intakes following a south-tonorth geographical gradient. When stratified by regions, total flavan-3-ol intake in the UK was about 2-fold that of the MED region. This relatively steep gradient in flavan-3-ol intake was mainly due to higher intakes of theaflavins and epigallocatechins in northern EPIC cohorts; indeed the main source of these subclasses of flavan-3-ols was found to be tea. On the other hand, PA intake was found to be statistically higher in the MED region, although large differences were also noted among centres within the same region. The main source of PA in the MED region was non-citrus fruit, chiefly apples and pears, followed by wine, similar to what was previously reported for the EPIC Spanish cohort ${ }^{(23)}$. Furthermore, the almost-nil intake of theaflavins in Greece, Spain and southern Italy indicates minimal consumption of tea in these countries. Even so, the major sources identified for the total and individual flavanols, PA and theaflavins were quite similar except in the UK where pulses also formed a considerable food source of PA.
A well-established inverse geographical gradient of CVD mortality exists ${ }^{(42)}$, which may seem paradoxical with the north-to-south gradient for flavan-3-ol intake and the observed beneficial effects of these compounds and flavonoid-rich foods against $\mathrm{CVD}^{(13,15,16)}$. Though far-fetched at this point to imply that flavan-3-ols have a significant role in CVD, a few factors could be considered to help elucidate this. Despite their higher observed antioxidant activity in vitro ${ }^{(43,44)}$, galloylated flavan-3-ol monomers (mainly found in fermented/black teas) have lower bioavailability than non-galloylated monomers ${ }^{(3,44)}$ (found more commonly in non-citrus fruit, green tea and cocoa). However, it is more likely that other risk factors of CVD may be more prevalent in the northern countries, such as high intake of SFA ${ }^{(45)}$, low intake of MUFA $^{(46)}$, low intake of fruits and vegetables ${ }^{(47)}$, low wine consumption ${ }^{(48)}$, sedentary lifestyle ${ }^{(49,50)}$ and social class influences ${ }^{(51)}$.

The present study also demonstrated that statistical differences exist in flavan-3-ol intakes among groups with different socio-demographic, anthropometric and lifestyle characteristics. Consumption of total flavan-3-ols, monomers and PA increased with age up to about 64 years of age and then it fell slightly. Similar results were seen in Spanish-EPIC ${ }^{(23)}$, $\mathrm{US}^{(8,22)}$ and Australian ${ }^{(52)}$ studies in adults. The intakes were significantly higher in former and never smokers. Since the major sources were tea and fruits, respectively, this suggests possible interaction between the consumption of these food sources and smoking habits ${ }^{(53,54)}$. Additionally, two case-control studies suggested that a flavonoid-rich diet may protect against pancreatic and lung cancer in smokers only ${ }^{(55,56)}$. Total flavan-3-ol intakes have been shown to be significantly associated with a slower increase of BMI in women in The Netherlands Cohort Study after adjusting for confounders 
Table 3. Major food sources of dietary flavan-3-ols, their monomers, proanthocyanidins (PA) and theaflavins in the Mediterranean (MED), non-Mediterranean (non-MED) and UK regions*

\begin{tabular}{|c|c|c|c|c|c|c|c|c|c|c|c|c|c|c|c|c|c|c|c|c|c|}
\hline \multirow[b]{2}{*}{ Food groups and foods } & \multicolumn{3}{|c|}{ Total flavan-3-ols (\%) } & \multicolumn{3}{|c|}{ Monomers (\%) } & \multicolumn{3}{|c|}{ Catechins (\%) } & \multicolumn{3}{|c|}{ Epicatechins (\%) } & \multicolumn{3}{|c|}{ EGC (\%)† } & \multicolumn{3}{|c|}{ PA (\%) } & \multicolumn{3}{|c|}{ Theaflavins (\%)‡ } \\
\hline & MED & $\begin{array}{l}\text { Non- } \\
\text { MED }\end{array}$ & UK & MED & $\begin{array}{l}\text { Non- } \\
\text { MED }\end{array}$ & UK & MED & $\begin{array}{l}\text { Non- } \\
\text { MED }\end{array}$ & UK & MED & $\begin{array}{l}\text { Non- } \\
\text { MED }\end{array}$ & UK & MED & $\begin{array}{l}\text { Non- } \\
\text { MED }\end{array}$ & UK & Med & $\begin{array}{l}\text { Non- } \\
\text { MED }\end{array}$ & UK & MED & $\begin{array}{l}\text { Non- } \\
\text { MED }\end{array}$ & UK \\
\hline Coffee, tea, herbal teas & 8.2 & $28 \cdot 8$ & 51.8 & 36.5 & $69 \cdot 2$ & $83 \cdot 7$ & 5.8 & $19 \cdot 4$ & $47 \cdot 7$ & 7.7 & $26 \cdot 1$ & $41 \cdot 8$ & 81.9 & 93.7 & $96 \cdot 4$ & $1 \cdot 2$ & $5 \cdot 0$ & $15 \cdot 0$ & $100 \cdot 0$ & $100 \cdot 0$ & $100 \cdot 0$ \\
\hline Coffee & 0.0 & 0.2 & 0.1 & 0.2 & 0.5 & 0.3 & 0.0 & 0.0 & 0.0 & 0.4 & 1.4 & 1.3 & 0.3 & 0.4 & 0.2 & 0.0 & 0.0 & 0.0 & 0.0 & 0.0 & 0.0 \\
\hline Tea & 7.9 & $28 \cdot 0$ & $51 \cdot 3$ & 34.7 & $66 \cdot 8$ & $82 \cdot 6$ & $5 \cdot 6$ & $19 \cdot 1$ & 47.5 & $7 \cdot 3$ & $24 \cdot 7$ & $40 \cdot 4$ & $77 \cdot 7$ & $90 \cdot 5$ & $95 \cdot 1$ & $1 \cdot 2$ & $5 \cdot 0$ & $15 \cdot 0$ & $100 \cdot 0$ & $100 \cdot 0$ & $100 \cdot 0$ \\
\hline Herbal tea & 0.3 & 0.6 & 0.4 & 1.6 & 1.9 & 0.8 & 0.1 & 0.3 & 0.2 & 0.0 & 0.1 & 0.0 & 4.0 & $2 \cdot 8$ & $1 \cdot 1$ & 0.0 & 0.0 & 0.0 & 0.0 & 0.0 & 0.0 \\
\hline Wine & 17.4 & $10 \cdot 2$ & $6 \cdot 1$ & $18 \cdot 1$ & $6 \cdot 3$ & 2.8 & 41.0 & 24.5 & $15 \cdot 8$ & $18 \cdot 6$ & 11.4 & $7 \cdot 7$ & 0.8 & 0.2 & 0.1 & $17 \cdot 3$ & $12 \cdot 6$ & $10 \cdot 0$ & 0.0 & 0.0 & 0.0 \\
\hline Beer, cider & 3.4 & $3 \cdot 1$ & $3 \cdot 2$ & $2 \cdot 1$ & 3.6 & 1.3 & 5.9 & 16.5 & 3.9 & 0.9 & 2.5 & 0.6 & 0.2 & 0.6 & $1 \cdot 0$ & $3 \cdot 7$ & 3.0 & 5.5 & 0.0 & 0.0 & 0.0 \\
\hline Milk beverages & 0.0 & 0.1 & $2 \cdot 4$ & 0.0 & 0.0 & $2 \cdot 3$ & 0.0 & 0.1 & $4 \cdot 2$ & 0.0 & 0.1 & $12 \cdot 4$ & 0.0 & 0.0 & 0.3 & 0.0 & 0.1 & 2.9 & 0.0 & 0.0 & 0.0 \\
\hline Fruit and vegetable juices & 0.5 & $2 \cdot 3$ & 0.9 & 0.3 & 1.4 & 0.4 & 0.3 & $2 \cdot 0$ & 0.7 & 0.6 & $6 \cdot 0$ & 2.5 & 0.0 & 0.0 & 0.1 & 0.5 & 2.8 & 1.5 & 0.0 & 0.0 & 0.0 \\
\hline $\begin{array}{l}\text { Carbonated/soft/isotonic } \\
\text { drinks, diluted syrups }\end{array}$ & 0.0 & $2 \cdot 2$ & 0.2 & 0.0 & 0.2 & 0.0 & 0.0 & 0.7 & 0.1 & 0.0 & 0.3 & 0.1 & 0.0 & 0.1 & 0.0 & 0.0 & 3.3 & 0.3 & 0.0 & 0.0 & 0.0 \\
\hline Fruit & $56 \cdot 2$ & $34 \cdot 1$ & 19.9 & 31.8 & $10 \cdot 2$ & 4.8 & $38 \cdot 1$ & $24 \cdot 2$ & $18 \cdot 9$ & 54.9 & $29 \cdot 1$ & 17.9 & 9.0 & 1.6 & 0.5 & $62 \cdot 3$ & $48 \cdot 0$ & 37.2 & 0.0 & 0.0 & 0.0 \\
\hline Apple and pear & 33.0 & $21 \cdot 8$ & 11.5 & $17 \cdot 2$ & $5 \cdot 7$ & $2 \cdot 1$ & $11 \cdot 1$ & $6 \cdot 0$ & $2 \cdot 0$ & $38 \cdot 2$ & $22 \cdot 6$ & 13.5 & 5.4 & 1.0 & 0.3 & 36.8 & 31.0 & $22 \cdot 0$ & 0.0 & 0.0 & 0.0 \\
\hline Stone fruits & 13.9 & 4.7 & $2 \cdot 7$ & 8.8 & 1.4 & 0.6 & $15 \cdot 1$ & $4 \cdot 0$ & $2 \cdot 4$ & $11 \cdot 3$ & 3.4 & 1.7 & $2 \cdot 2$ & 0.2 & 0.1 & $15 \cdot 2$ & 6.6 & $5 \cdot 1$ & 0.0 & 0.0 & 0.0 \\
\hline Grape & 5.0 & $2 \cdot 3$ & $2 \cdot 0$ & 3.5 & 0.9 & 0.5 & 5.8 & $2 \cdot 6$ & $2 \cdot 3$ & 4.4 & 1.9 & 1.7 & 1.0 & 0.2 & 0.1 & $5 \cdot 4$ & $3 \cdot 1$ & 3.7 & 0.0 & 0.0 & 0.0 \\
\hline Berries & $3 \cdot 1$ & 3.4 & $2 \cdot 0$ & 0.7 & 0.6 & 0.3 & 1.6 & $2 \cdot 6$ & 1.5 & 0.3 & 0.7 & 0.4 & 0.3 & 0.1 & 0.1 & $3 \cdot 7$ & 4.9 & 3.9 & 0.0 & 0.0 & 0.0 \\
\hline Banana & 0.3 & 0.7 & 0.8 & $1 \cdot 2$ & 1.4 & $1 \cdot 2$ & 3.9 & 8.3 & $10 \cdot 0$ & 0.0 & 0.0 & 0.0 & 0.0 & 0.0 & 0.0 & 0.1 & 0.4 & 0.6 & 0.0 & 0.0 & 0.0 \\
\hline Citrus fruit & 0.0 & 0.0 & 0.0 & 0.0 & 0.0 & 0.0 & 0.0 & 0.0 & 0.0 & 0.0 & 0.0 & 0.0 & 0.0 & 0.0 & 0.0 & 0.0 & 0.0 & 0.0 & 0.0 & 0.0 & 0.0 \\
\hline Kiwi & 0.2 & 0.1 & 0.1 & 0.1 & 0.0 & 0.0 & 0.0 & 0.0 & 0.0 & 0.2 & 0.1 & $0 \cdot 1$ & 0.0 & 0.0 & 0.0 & 0.3 & 0.2 & 0.1 & 0.0 & 0.0 & 0.0 \\
\hline Other fruits & 0.7 & $1 \cdot 1$ & 0.8 & 0.3 & 0.2 & 0.1 & 0.6 & 0.6 & 0.7 & 0.5 & 0.4 & 0.4 & 0.1 & 0.0 & 0.0 & 0.7 & 1.7 & 1.7 & 0.0 & 0.0 & 0.0 \\
\hline $\begin{array}{l}\text { Chocolate candy/bars, } \\
\text { paste, confetti }\end{array}$ & 4.7 & $5 \cdot 7$ & $3 \cdot 2$ & $5 \cdot 6$ & $4 \cdot 2$ & 1.3 & 3.5 & 4.6 & $2 \cdot 1$ & $9 \cdot 2$ & $12 \cdot 2$ & $5 \cdot 7$ & $4 \cdot 3$ & $2 \cdot 0$ & 0.5 & 4.6 & 6.6 & 5.5 & 0.0 & 0.0 & 0.0 \\
\hline $\begin{array}{l}\text { Cakes, sweet pies, pastries, } \\
\text { puddings }\end{array}$ & $2 \cdot 3$ & 3.1 & 3.4 & $2 \cdot 4$ & 1.9 & 1.3 & 1.7 & 3.1 & $2 \cdot 9$ & $5 \cdot 0$ & $8 \cdot 3$ & 7.5 & $2 \cdot 2$ & 1.3 & 0.8 & $3 \cdot 1$ & $5 \cdot 8$ & 7.6 & 0.0 & 0.0 & 0.0 \\
\hline Pulses & 1.8 & 0.5 & 3.5 & $0 \cdot 2$ & 0.0 & 0.1 & 0.5 & 0.2 & 0.7 & 0.1 & 0.0 & $0 \cdot 1$ & 0.0 & 0.0 & 0.0 & $2 \cdot 2$ & 0.7 & $7 \cdot 1$ & 0.0 & 0.0 & 0.0 \\
\hline Cereal and cereal products & 0.1 & 0.6 & 1.1 & 0.1 & 0.1 & 0.2 & 0.1 & 0.4 & 0.7 & 0.1 & 0.3 & 0.5 & 0.0 & 0.0 & 0.0 & $2 \cdot 1$ & 3.8 & 3.5 & 0.0 & 0.0 & 0.0 \\
\hline Soups & 0.0 & $2 \cdot 8$ & 0.0 & 0.0 & 0.3 & 0.0 & 0.0 & $1 \cdot 1$ & 0.0 & 0.0 & 0.4 & 0.0 & 0.0 & 0.0 & 0.0 & 0.0 & $4 \cdot 3$ & 0.0 & 0.0 & 0.0 & 0.0 \\
\hline Other foods and beverages & 5.4 & 6.5 & 4.3 & $2 \cdot 9$ & $2 \cdot 6$ & 1.8 & $3 \cdot 0$ & $3 \cdot 3$ & $2 \cdot 2$ & 2.9 & 3.4 & $3 \cdot 2$ & 1.5 & 0.6 & 0.4 & $3 \cdot 0$ & 3.9 & 3.9 & 0.0 & 0.0 & 0.0 \\
\hline
\end{tabular}

EGC, (epi)gallocatechins.

*Values are percentages derived from models adjusted for centre, age and sex, and weighted by season and day of recall.

† Sum of epigallocatechin, epicatechin 3-gallate, epigallocatechin 3-gallate, gallocatechin and catechin-3-gallate.

$\ddagger$ Sum of theaflavin, theaflavin-3'-gallate, theaflavin-3 gallate and theaflavin-3,3'-digallate. 
Table 4. Socio-demographic, lifestyle and anthropometric determinants of intake $(\mathrm{mg} / \mathrm{d})$ of total flavan-3-ols and their subgroups* (Mean values with their standard errors)

\begin{tabular}{|c|c|c|c|c|c|c|c|c|c|c|c|c|c|}
\hline & \multirow[b]{2}{*}{$n$} & \multicolumn{3}{|c|}{ Total flavan-3-ols } & \multicolumn{3}{|c|}{ Monomers† } & \multicolumn{3}{|c|}{ Proanthocyanidins } & \multicolumn{3}{|c|}{ Theaflavins $\ddagger$} \\
\hline & & Mean & SE & $P \S$ & Mean & $\mathrm{SE}$ & $P \S$ & Mean & SE & $P \S$ & Mean & SE & $P \S$ \\
\hline Region & & & & $<0.001$ & & & $<0.001$ & & & $<0.001$ & & & $<0.001$ \\
\hline Mediterranean countries & 11285 & 268.8 & $2 \cdot 6$ & & $50 \cdot 0$ & 1.0 & & $217 \cdot 2$ & $2 \cdot 2$ & & 1.6 & 0.1 & \\
\hline Non-Mediterranean countries & 23469 & 274.7 & 1.9 & & $90 \cdot 2$ & .7 & & $177 \cdot 9$ & 1.5 & & 6.5 & 0.1 & \\
\hline UK & 1283 & $406 \cdot 6$ & $7 \cdot 6$ & & $182 \cdot 4$ & 3.0 & & 198.4 & $6 \cdot 3$ & & $25 \cdot 9$ & 0.3 & \\
\hline Sex & & & & $<0.001$ & & & 0.002 & & & $<0.001$ & & & 0.019 \\
\hline Male & 13028 & $280 \cdot 7$ & 3.0 & & 73.6 & 1.2 & & 201.6 & 2.5 & & 5.5 & 0.1 & \\
\hline Female & 23009 & 296.5 & $2 \cdot 2$ & & $78 \cdot 1$ & 0.9 & & 212.5 & 1.8 & & 5.9 & 0.1 & \\
\hline Age (years) & & & & $<0.001$ & & & 0.004 & & & $<0.001$ & & & 0.340 \\
\hline $35-44$ & 3335 & $262 \cdot 6$ & $5 \cdot 0$ & & $72 \cdot 2$ & $2 \cdot 0$ & & $185 \cdot 0$ & $4 \cdot 1$ & & $5 \cdot 4$ & 0.2 & \\
\hline $45-54$ & 12595 & 274.9 & $2 \cdot 7$ & & 73.9 & $1 \cdot 1$ & & $195 \cdot 2$ & $2 \cdot 2$ & & $5 \cdot 7$ & 0.1 & \\
\hline $55-64$ & 14940 & $302 \cdot 5$ & 2.6 & & $78 \cdot 1$ & 1.0 & & $218 \cdot 7$ & $2 \cdot 1$ & & 5.7 & 0.1 & \\
\hline $65-74$ & 5167 & $298 \cdot 3$ & $4 \cdot 3$ & & $76 \cdot 7$ & 1.7 & & $215 \cdot 7$ & 3.6 & & 5.9 & 0.2 & \\
\hline Education level completed & & & & $<0.001$ & & & $<0.001$ & & & $<0.001$ & & & $<0.001$ \\
\hline None & 1709 & 267.4 & $7 \cdot 7$ & & $69 \cdot 6$ & 3.0 & & 192.5 & 6.4 & & 5.4 & 0.3 & \\
\hline Primary & 10469 & 258.0 & 3.0 & & $59 \cdot 4$ & $1 \cdot 2$ & & 194.1 & 2.5 & & 4.4 & 0.1 & \\
\hline Technical/professional & 8038 & $281 \cdot 1$ & 3.5 & & $72 \cdot 0$ & 1.4 & & 204.0 & 2.9 & & $5 \cdot 1$ & 0.1 & \\
\hline Secondary school & 7152 & 303.1 & 3.5 & & 82.1 & 1.4 & & $215 \cdot 1$ & 2.9 & & 6.0 & 0.1 & \\
\hline Post-secondary & 8155 & 329.6 & 3.3 & & $96 \cdot 3$ & 1.3 & & $225 \cdot 7$ & $2 \cdot 8$ & & $7 \cdot 7$ & 0.1 & \\
\hline Smoking status & & & & $<0.001$ & & & $<0.001$ & & & $<0.001$ & & & $<0.001$ \\
\hline Never & 17483 & 295.5 & 2.5 & & 79.8 & 1.0 & & 209.8 & $2 \cdot 0$ & & $6 \cdot 0$ & 0.1 & \\
\hline Former & 10288 & 301.4 & 2.9 & & $80 \cdot 2$ & 1.2 & & $215 \cdot 0$ & 2.4 & & $6 \cdot 2$ & 0.1 & \\
\hline Smoker & 7726 & $256 \cdot 1$ & 3.3 & & $62 \cdot 4$ & $1 . \overline{3}$ & & $189 \cdot 3$ & $2 \cdot 7$ & & 4.5 & 0.1 & \\
\hline Physical activity & & & & $<0.001$ & & & $<0.001$ & & & $<0.001$ & & & 0.002 \\
\hline Inactive & 7463 & 274.5 & 3.2 & & 71.9 & 1.3 & & $197 \cdot 3$ & $2 \cdot 6$ & & $5 \cdot 3$ & 0.1 & \\
\hline Moderately inactive & 11969 & 283.8 & 2.6 & & $75 \cdot 0$ & 1.1 & & $203 \cdot 1$ & $2 \cdot 1$ & & $5 \cdot 7$ & 0.1 & \\
\hline Moderately active & 8400 & 299.1 & 3.1 & & $79 \cdot 0$ & 1.3 & & $214 \cdot 1$ & 2.5 & & $6 \cdot 1$ & 0.1 & \\
\hline Active & 6380 & 304.5 & 3.5 & & $79 \cdot 1$ & 1.5 & & $219 \cdot 6$ & $2 \cdot 8$ & & $5 \cdot 8$ & 0.2 & \\
\hline $\operatorname{BMI}\left(\mathrm{kg} / \mathrm{m}^{2}\right)$ & & & & $<0.001$ & & & $<0.001$ & & & 0.012 & & & $<0.001$ \\
\hline$<25$ & 16854 & $297 \cdot 1$ & $2 \cdot 6$ & & $81 \cdot 6$ & 1.0 & & $209 \cdot 3$ & $2 \cdot 1$ & & $6 \cdot 3$ & 0.1 & \\
\hline 25 to $<30$ & 13766 & 285.2 & $2 \cdot 6$ & & 72.5 & 1.0 & & $207 \cdot 3$ & $2 \cdot 1$ & & 5.4 & 0.1 & \\
\hline$>30$ & 5417 & $270 \cdot 0$ & 3.9 & & $66 \cdot 8$ & 1.6 & & 198.4 & $3 \cdot 2$ & & 4.7 & 0.2 & \\
\hline
\end{tabular}

* General linear model adjusted for age, sex, region, BMI (whenever not stratified for the respective variables) and energy intake, and weighted by season and day of recall. † Sum of catechins, epicatechins and (epi)gallocatechins.

$\ddagger$ Sum of theaflavin, theaflavin-3'-gallate, theaflavin-3 gallate and theaflavin-3,3'-digallate.

$\S P$ values are for overall differences in mean consumption by general linear model among the socio-demographic, lifestyle and anthropometric subgroups.

including dieting, and some healthy habits such as fruit and vegetable intake ${ }^{(57)}$. Our study showed that the intakes of total and subclasses of flavan-3-ols were lower in obese subjects and, in addition, higher in physically active subjects. Further investigation explaining the association between all these factors and their role in obesity is needed. In our study, intakes of PA increased with higher level of education, and were found to be considerably low in the group without formal schooling. In line with our findings, consumption of fruits, fruit juice, wine and tea has been previously associated with higher socio-economic status ${ }^{(58)}$. These factors should be taken into consideration when looking at disease prevention, planning of healthy diets within a specific population and may also be instrumental when establishing 'lifespan essential' dietary reference intakes for flavan-3-ols, PA and theaflavins in different populations, and in subgroups with unfavourable lifestyle factors ${ }^{(59)}$

Major differences in total flavan-3-ol intake can be observed between our study and other descriptive studies (Table 5). Our estimates of total flavan-3-ol intake were much higher than those reported in other countries and the main reason being that some individual compounds or subclasses of flavan-3-ols were not included in the total estimation of flavan-3-ols in those studies. Comparison of the subclasses (monomers, PA and theaflavins) may therefore be preferable. Even then, the intakes may vary because of other important factors involved in the estimation, such as different methodologies used to assess dietary intake of cohorts (FFQ, 24HDR, diet history, etc); compositional data of the compounds may come from different sources or from older versions of the USDA database ${ }^{(23,60)}$, or the median intake reported rather than the mean. The latter is particularly the case in the Greek EPIC study ${ }^{(61)}$. Finally, cohort characteristics, especially those that are associated with flavan-3-ol consumption (e.g. age and sex) may vary considerably. All these are to be kept in mind when making comparisons. Flavan-3-ol monomer intake reported recently for the UK and Ireland by Beking \& Vieira $^{(62)}$ and based on food balance sheets was about onethird that of our reported intake for the UK region. The monomer intake reported in an elderly Dutch cohort ${ }^{(63)}$ as closer but still slightly lower than our estimates for the Dutch cohorts of Bilthoven and Utrecht even though, in our study, intakes were found to be higher in older age groups. Monomer intakes reported recently in Italy ${ }^{(21)}$ and for Spanish ${ }^{(23)}$ and Greek $^{(61)}$ EPIC cohorts were within our ranges for those countries. As for other countries known to have a tea culture, 
Table 5. Previously estimated daily flavan-3-ol intakes (mg) in adults in several countries*

\begin{tabular}{|c|c|c|c|c|c|c|c|c|c|c|c|}
\hline Country & $\begin{array}{c}\text { Total flavan-3- } \\
\text { ols (mg/d) }\end{array}$ & $\begin{array}{l}\text { Compounds included } \\
\text { in the total flavan-3-ols }\end{array}$ & $\begin{array}{c}\text { Flavan-3-ol } \\
\text { monomers } \\
(\mathrm{mg} / \mathrm{d})\end{array}$ & $\begin{array}{c}\mathrm{C} \\
(\mathrm{mg} / \mathrm{d})\end{array}$ & $\begin{array}{c}\mathrm{EC} \\
(\mathrm{mg} / \mathrm{d})\end{array}$ & $\begin{array}{l}E G C \\
(\mathrm{mg} / \mathrm{d})\end{array}$ & $\begin{array}{c}\mathrm{PA} \\
(\mathrm{mg} / \mathrm{d})\end{array}$ & $\begin{array}{c}\text { Theaflavins } \\
(\mathrm{mg} / \mathrm{d})\end{array}$ & $\begin{array}{l}\text { Source of } \\
\text { compositional data }\end{array}$ & $\begin{array}{l}\text { Study population } \\
\text { (sample size/age } \\
\text { (years)/sex) }\end{array}$ & $\begin{array}{l}\text { Dietary assessment } \\
\text { method }\end{array}$ \\
\hline Finland $^{(66)}$ & 128 & $C, E C, P A$ & 12 & ns & ns & - & 116 & - & $\begin{array}{l}\text { National Finnish } \\
\text { database }\end{array}$ & 2007/25-64/both & $48 \mathrm{DR}$ \\
\hline Ireland ${ }^{(62)}$ & 47 & $C, E C, E G C$ & 47 & ns & ns & ns & - & - & $\begin{array}{l}\text { USDA } 2007 \text { and } \\
\text { various other }\end{array}$ & $\mathrm{ns} / \mathrm{ns} / \mathrm{ns}$ & Food balance sheets \\
\hline $\mathrm{UK}^{(62)}$ & 52 & C, EC, EGC & 52 & ns & ns & ns & - & - & $\begin{array}{l}\text { USDA } 2007 \text { and } \\
\text { various other }\end{array}$ & $\mathrm{ns} / \mathrm{ns} / \mathrm{ns}$ & Food balance sheets \\
\hline$U K^{(64)} \dagger$ & 154 & $C, E C, E G C, P A$ & 119 & 7 & 25 & 88 & 34 & - & Various & $404 / 32-88 /$ both & FFQ \\
\hline Denmark $^{(52)}$ & 148 & $\begin{array}{l}\text { C, EC, EGC, theaflavins, } \\
\text { thearubigins }\end{array}$ & ns & ns & ns & ns & - & ns & USDA 2003 & ns/ns/both & Dietary history \\
\hline The Netherlands ${ }^{(52)}$ & 145 & $\begin{array}{l}\text { C, EC, EGC, theaflavins, } \\
\text { thearubigins }\end{array}$ & ns & ns & ns & ns & - & ns & USDA 2003 & 6200/1-92/both & $2 \mathrm{~d}$ dietary record \\
\hline The Netherlands ${ }^{(63)}$ & 72 & C, EC, EGC & 72 & ns & ns & ns & - & - & Own data & $1266 / 65-84 /$ men & 1-month dietary history \\
\hline France ${ }^{(65)}$ & 338 & $C, E C, E G C, P A$ & 87 & ns & ns & ns & 227 & 9 & Phenol-Explorer & $13017 / 35-60 /$ both & 24DR \\
\hline Italy ${ }^{(21)}$ & 343 & $\begin{array}{l}\text { C, EC, EGC, PA, } \\
\text { theaflavins, thearubigins }\end{array}$ & 53 & ns & ns & ns & 290 & ns & USDA 2003, 2004 & 547/22-80/both & $\mathrm{FFQ}$ \\
\hline Spain EPIC ${ }^{(23)}$ & 221 & $\begin{array}{l}C, E C, E G C \text {, theaflavins, } \\
\text { thearubigins }\end{array}$ & 30 & 13 & 11 & 6 & 189 & 0 & USDA 2004, 2007 & $40683 / 35-64 /$ both & FFQ \\
\hline Greece EPIC ${ }^{(61)} \ddagger$ & 89 & $C, E C, E C G, P A$ & 13 & 6 & 6 & 1 & 75 & - & USDA 2004, 2007 & 28572/30-76/both & FFQ \\
\hline$U_{S A}^{(22,67)}$ & 251 & $\begin{array}{l}\text { (C, EC, theaflavins, } \\
\text { thearubigins), PA }\end{array}$ & ns & ns & ns & ns & 95 & ns & USDA 2004, 2007 & $8809 / 19+/$ both & $24 \mathrm{DR}$ \\
\hline Australia $^{(52)}$ & 422 & $\begin{array}{l}\text { C, EC, EGC, theaflavins, } \\
\text { thearubigins }\end{array}$ & 188 & 9 & 17 & 162 & - & 22 & USDA 2003 & $17326 / 19+/$ both & $24 \mathrm{DR}$ \\
\hline $\operatorname{Japan}^{(60)}$ & 380 & $C, E C, E G C$ & 380 & ns & ns & ns & - & - & $\begin{array}{l}\text { National Japanese } \\
\text { database }\end{array}$ & $514 / 40+/$ women & $24 \mathrm{~h}$ dietary record \\
\hline
\end{tabular}

C, catechins; EC, epicatechins; EGC, (epi)gallocatechins; PA, proanthocyanidins; ns, not specified; -, value not provided by the original study; DR, dietary recall; USDA, US Department of Agriculture. *Where applicable and when not provided by the study, total flavan-3-ols were calculated as the sum of the subgroups.

$\ddagger$ Total flavan-3-ols were calculated as the sum of the values in Rossi et al. ${ }^{(21)}$ for C, EC, theaflavins and thearubigins combined and in Wang et al. ${ }^{(67)}$ for PA. 
Otaki et al. $^{(60)}$ have estimated monomer intake in Japanese women to be around $380 \mathrm{mg} / \mathrm{d}$, more than double the value we reported for the UK region. This is probably because of higher consumption of non-fermented tea, such as green tea, in Japan. Green tea is a rich source of flavan-3-ol monomers but not a source of theaflavins, which was found exclusively in black tea, the tea more commonly consumed in the UK. In contrast, monomer intake $(188 \mathrm{mg} / \mathrm{d})$ reported in Australia was comparable to our value in the UK region. PA intake for Spain in our study is slightly higher than previously reported for the EPIC Spain cohort; however, the previous study used dietary history questionnaires and only the USDA food composition values in their estimation of flavan-3-ols ${ }^{\text {(23) }}$. A recent Italian case-control study assessed the mean PA intake to be around $290 \mathrm{mg} / \mathrm{d}$ which is within the range of the Italian values in our study ${ }^{(21)}$. However, most PA estimations have been done in case-control studies, which assess small groups of controls and not always all the subgroups of PA were included ${ }^{(20,21,64)}$. Surprisingly, Greece being a MED country had the lowest intake of PA of all EPIC centres. Among the other previously mentioned factors for this difference, this finding is also supported by the lower consumption of fruit in Greece compared to Italy and Spain reported previously in EPIC studies ${ }^{(47)}$. Perez-Jimenez et al. ${ }^{(65)}$ reported intakes of flavan-3-ol monomers $(114 \mathrm{mg} / \mathrm{d})$, PA $(191 \mathrm{mg} / \mathrm{d})$ and theaflavins $(16 \mathrm{mg} / \mathrm{d})$ in French women that are within the range of our values for the French EPIC centres. A limited number of descriptive studies is available on PA to facilitate a comparison with non-EPIC countries. Using their own composition database, Ovaskainen et al. ${ }^{(66)}$ reported lower PA intakes for a Finnish population compared to the northern EPIC countries such as Sweden and Norway. The sources of PA in northern EPIC countries were found to be similar to those in Finland, with the exception of berries, which were not singled out in our study but were an important source of PA in Finland. These differences in intake and food sources compared to our study are most probably due to the varying study variables already exposed earlier. Finally, Wang et $a l .{ }^{(67)}$ recently estimated PA intake for the US population to be about $95 \mathrm{mg} / \mathrm{d}$. This is still slightly lower than the lowest intakes found in our study (Greek cohorts). Clearly, more consistent methods of intake estimation between and within countries are needed. Parallel to that, improved methods for identification and quantification of some flavan3-ol compounds, such as thearubigins, are needed to allow for more exhaustive flavonoid composition databases.

The use of a common expanded flavonoid database provided us with greater coverage of foods representative of the EPIC countries while allowing for comparisons of results across the countries. Despite the fact that we applied retention factors to foods prepared by cooking, we estimated higher intakes than in the previous studies. Moreover, our values are likely to be underreported due to spices and herbs often not accounted for during diet assessment and because a small proportion (2-16\%) of flavan-3-ol analytical values in our study was still missing. The underestimation of intakes is also probably due to the omission of dietetic supplements in this analysis. However, few consumers of herb/plant supplements participated in this study (the highest was 5\% reported in Denmark) ${ }^{(68)}$.

To our knowledge, this is the largest study to date describing flavan-3-ol and PA intake across several European countries. Since not all the EPIC cohorts are representative of the population, the observed level of intake cannot be extrapolated to the general population of each region.

In summary, this study provides total and individual flavan3-ol, PA and theaflavin intakes for ten EPIC countries by sex and EPIC centre. The major dietary contributors of these flavonoid subclasses are described by the MED, non-MED and UK regions. In addition, we show that socio-demographic, anthropometric and lifestyle factors associated with differential consumption of flavan-3-ols, PA and theaflavins exist. Combined with more elucidated information on the bioavailability of these compounds, these descriptive data will be valuable in future evaluations of total and individual flavan-3-ols and their role in health and disease in the European population.

\section{Acknowledgements}

The present work was carried out with the financial support of the European Commission: Public Health and Consumer Protection Directorate 1993-2004; Research DirectorateGeneral 2005; Ligue contre le Cancer, Institut Gustave Roussy, Mutuelle Générale de l'Education Nationale, Institut National de la Santé et de la Recherche Médicale (INSERM, France); German Cancer Aid; German Cancer Research Centre; German Federal Ministry of Education and Research; Danish Cancer Society: Health Research Fund (FIS) of the Spanish Ministry of Health (RTICC (DR06/0020); the participating regional governments and institutions of Spain; Cancer Research UK; Medical Research Council, UK; the Stroke Association, UK; British Heart Foundation; Department of Health, UK; Food Standards Agency, UK; the Wellcome Trust, UK; Hellenic Ministry of Health; the Stavros Niarchos Foundation and the Hellenic Health Foundation; Italian Association for Research on Cancer; Compagnia San Paolo, Italy; Dutch Ministry of Public Health, Welfare and Sports; Dutch Ministry of Health; Dutch Prevention Funds; LK Research Funds; Dutch ZON (Zorg Onderzoek Nederland); World Cancer Research Fund (WCRF); Swedish Cancer Society; Swedish Scientific Council; Regional Government of Skane, Sweden; Nordforsk - Centre of Excellence programme. Some authors are partners of ECNIS, a network of excellence of the 6FP of the EC. R Z.-R. is thankful for a postdoctoral programme Fondo de Investigación Sanitaria (FIS; no. CD09/00133) from the Spanish Ministry of Science and Innovation. The authors thank Raul M. García for developing an application to link the FCDB and the 24-HDR. The authors declare that there are no conflicts of interest. The authors' contributions are as follows: R. Z.-R. and C. A. G. designed the research; V. K. and R. Z.-R. conducted the research; V. K. and L. L.-B. performed the statistical analysis; V. K. and R. Z.-R. wrote the manuscript. V. K., R. Z.-R., L. L.-B., I. R., A. S., N. S., E. R., C. T. M. v. R., H. B. B.-d. M., A. T., V. D., K. T., G. S., 
D. E., J. R. Q., E. M., J. M. H., F. C., E. W., U. E., P. H. M. P, R. K., B. T., G. J., I. J., R. T., H. B., D. D., P. A., A. M., K.-T. K., R. L., V. Kr., E. A., C. S., S. S., K. O., A. T., A. O., M.-C. B.-R., G. F., F. P. and C. A. G. read, critically reviewed and approved the final manuscript.

\section{References}

1. Santos-Buelga C \& Scalbert A (2000) Proanthocyanidins and tannin-like compounds - nature, occurence, dietary intake and effects on nutrition and health. J Sci Food Agric 80, $1094-1117$.

2. Laura A de la Rosa, E Alvarez-Parrilla and GA GonzálezAguilar (editors) (2010) Fruit and Vegetable Phytochemicals, 1st ed. Ames, IA: Blackwell Publishing.

3. Manach C, Williamson G, Morand C, et al. (2005) Bioavailability and bioefficacy of polyphenols in humans. I. Review of 97 bioavailability studies. Am J Clin Nutr 81, 230S-242S.

4. Aron PM \& Kennedy JA (2007) Compositional investigation of phenolic polymers isolated from Vitis vinifera L. Cv. Pinot noir during fermentation. J Agric Food Chem 55, $5670-5680$

5. Hellstrom JK, Torronen AR \& Mattila PH (2009) Proanthocyanidins in common food products of plant origin. J Agric Food Chem 57, 7899-7906

6. Auger C, Al-Awwadi N, Bornet A, et al. (2004) Catechins and procyanidins in Mediterranean diets. Food Res Int 37, $233-245$.

7. Williamson G \& Manach C (2005) Bioavailability and bioefficacy of polyphenols in humans. Am J Clin Nutr 81, 243S-255S.

8. Gu L, Kelm MA, Hammerstone JF, et al. (2004) Concentrations of proanthocyanidins in common foods and estimations of normal consumption. J Nutr 134, 613-617.

9. Crozier A, Lean MEJ, McDonald MS, et al. (1997) Quantitative analysis of the flavonoid content of commercial tomatoes, onions, lettuce, and celery. J Agric Food Chem 45, 590-595.

10. Rickman JC, Barrett DM \& Bruhn CM (2007) Nutritional comparison of fresh, frozen and canned fruits and vegetables. Part 1. Vitamins $\mathrm{C}$ and $\mathrm{B}$ and phenolic compounds. J Sci Food Agric 87, 930-944.

11. Beecher GR (2003) Overview of dietary flavonoids: nomenclature, occurrence and intake. J Nutr 133, 3248S-3254S.

12. Ramiro-Puig E \& Castell M (2009) Cocoa: antioxidant and immunomodulator. Br J Nutr 101, 931-940.

13. Suzuki J, Isobe M, Morishita R, et al. (2009) Tea polyphenols regulate key mediators on inflammatory cardiovascular diseases. Mediators Inflamm 2009, article ID 494928; Epublication 19 July 2009.

14. Yang CS, Wang X, Lu G, et al. (2009) Cancer prevention by tea: animal studies, molecular mechanisms and human relevance. Nat Rev Cancer 9, 429-439.

15. Hooper L, Kroon PA, Rimm EB, et al. (2008) Flavonoids, flavonoid-rich foods, and cardiovascular risk: a meta-analysis of randomized controlled trials. Am J Clin Nutr 88, 38-50.

16. Williamson G, Sies H, Heber D, et al. (2009) Functional foods for health promotion: state-of-the-science on dietary flavonoids. Extended abstracts from the 12th Annual Conference on Functional Foods for Health Promotion, April 2009. Nutr Rev 67, 736-743.

17. Cos P, de Bruyne T, Hermans N, et al. (2004) Proanthocyanidins in health care: current and new trends. Curr Med Chem 11, $1345-1359$.

18. Schroeter H, Heiss C, Balzer J, et al. (2006) (-)-Epicatechin mediates beneficial effects of flavanol-rich cocoa on vascular function in humans. Proc Natl Acad Sci U S A $\mathbf{1 0 3}$ 1024-1029.

19. Monagas M, Urpi-Sarda M, Sánchez-Patán F, et al. (2010) Insights into the metabolism and microbial biotransformation of dietary flavan-3-ols and the bioactivity of their metabolites. Food Funct 1, 233-253.

20. Rossi M, Negri E, Parpinel M, et al. (2010) Proanthocyanidins and the risk of colorectal cancer in Italy. Cancer Causes Control 21, 243-250.

21. Rossi M, Rosato V, Bosetti C, et al. (2010) Flavonoids, proanthocyanidins, and the risk of stomach cancer. Cancer Causes Control 21, 1597-1604.

22. Chun OK, Chung SJ \& Song WO (2007) Estimated dietary flavonoid intake and major food sources of U.S. adults. J Nutr 137, 1244-1252.

23. Zamora-Ros R, Andres-Lacueva C, Lamuela-Raventós RM, et al. (2010) Estimation of dietary sources and flavonoid intake in a Spanish adult population (EPIC-Spain). $J \mathrm{Am}$ Diet Assoc 110, 390-398.

24. Slimani N, Kaaks R, Ferrari P, et al. (2002) European Prospective Investigation into Cancer and Nutrition (EPIC) calibration study: rationale, design and population characteristics. Public Health Nutr 5, 1125-1145.

25. Slimani N, Ferrari P, Ocke M, et al. (2000) Standardization of the 24-hour diet recall calibration method used in the European Prospective Investigation into Cancer and Nutrition (EPIC): general concepts and preliminary results. Eur J Clin Nutr 54, 900-917.

26. Slimani N, Deharveng G, Charrondiere RU, et al. (1999) Structure of the standardized computerized 24-h diet recall interview used as reference method in the 22 centers participating in the EPIC project. European Prospective Investigation into Cancer and Nutrition. Comput Methods Programs Biomed 58, 251-266.

27. Brustad M, Skeie G, Braaten T, et al. (2003) Comparison of telephone vs face-to-face interviews in the assessment of dietary intake by the $24 \mathrm{~h}$ recall EPIC SOFT program the Norwegian calibration study. Eur J Clin Nutr 57, $107-113$.

28. Kaaks R, Plummer M, Riboli E, et al. (1994) Adjustment for bias due to errors in exposure assessments in multicenter cohort studies on diet and cancer: a calibration approach. Am J Clin Nutr 59, 245S-2250.

29. Kaaks R, Riboli E \& van Staveren W (1995) Calibration of dietary intake measurements in prospective cohort studies. Am J Epidemiol 142, 548-556.

30. Kaaks R \& Riboli E (1997) Validation and calibration of dietary intake measurements in the EPIC project: methodological considerations. European Prospective Investigation into Cancer and Nutrition. Int J Epidemiol 26, Suppl. 1, S15-S25.

31. Haftenberger M, Schuit AJ, Tormo MJ, et al. (2002) Physical activity of subjects aged 50-64 years involved in the European Prospective Investigation into Cancer and Nutrition (EPIC). Public Health Nutr 5, 1163-1176.

32. Haftenberger M, Lahmann PH, Panico S, et al. (2002) Overweight, obesity and fat distribution in 50- to 64-yearold participants in the European Prospective Investigation into Cancer and Nutrition (EPIC). Public Health Nutr 5, $1147-1162$.

33. Riboli E, Hunt KJ, Slimani N, et al. (2002) European Prospective Investigation into Cancer and Nutrition (EPIC): study populations and data collection. Public Health Nutr 5 , 1113-1124.

34. Slimani N, Fahey M, Welch AA, et al. (2002) Diversity of dietary patterns observed in the European Prospective 
Investigation into Cancer and Nutrition (EPIC) project. Public Health Nutr 5, 1311-1328.

35. United States Department of Agriculture (2007) USDA Database for the Flavonoid Content of Selected Foods, release 2.1 ed. Beltsville, MD: USDA.

36. United States Department of Agriculture (2004) USDA Database for the Proanthocyanidin Content of Selected Foods. Beltsville, MD: USDA.

37. Neveu V, Perez-Jimenez J \& Vos F, et al. (2010) PhenolExplorer: an online comprehensive database on polyphenol contents in food. Database (Oxf), version 1.5.2. http://www. phenol-explorer.eu

38. Arts IC, van de Putte B \& Hollman PC (2000) Catechin contents of foods commonly consumed in The Netherlands. 1. Fruits, vegetables, staple foods, and processed foods. J Agric Food Chem 48, 1746-1751.

39. Zamora-Ros R, Knaze V, Lujan-Barroso L, et al. (2011) Estimation of the intake of anthocyanidins and their food sources in the European Prospective Investigation into Cancer and Nutrition (EPIC) study. Br J Nutr 106, 1090-1099.

40. Zamora-Ros R, Knaze V, Lujan-Barroso L, et al. (2011) Estimated dietary intakes of flavonols, flavanones and flavones in the European Prospective Investigation into Cancer and Nutrition (EPIC) 24 hour dietary recall cohort. Br J Nutr 106, 1915-1925.

41. Rechner AR, Wagner E, van Buren L, et al. (2002) Black tea represents a major source of dietary phenolics among regular tea drinkers. Free Radic Res 36, 1127-1135.

42. Levi F, Chatenoud L, Bertuccio P, et al. (2009) Mortality from cardiovascular and cerebrovascular diseases in Europe and other areas of the world: an update. Eur J Cardiovasc Prev Rehabil 16, 333-350.

43. Henning SM, Niu Y, Lee NH, et al. (2004) Bioavailability and antioxidant activity of tea flavanols after consumption of green tea, black tea, or a green tea extract supplement. Am J Clin Nutr 80, 1558-1564.

44. Auger C, Mullen W, Hara Y, et al. (2008) Bioavailability of polyphenon E flavan-3-ols in humans with an ileostomy. J Nutr 138, 1535S-1542S.

45. Linseisen J, Welch AA, Ocke M, et al. (2009) Dietary fat intake in the European Prospective Investigation into Cancer and Nutrition: results from the 24-h dietary recalls. Eur J Clin Nutr 63, Suppl. 4, S61-S80.

46. Lopez-Miranda J, Perez-Jimenez F, Ros E, et al. (2010) Olive oil and health: summary of the II international Aconference on olive oil and health consensus report, Jaén and Córdoba (Spain) 2008. Nutr Metab Cardiovasc Dis 20, 284-294.

47. Agudo A, Slimani N, Ocke MC, et al. (2002) Consumption of vegetables, fruit and other plant foods in the European Prospective Investigation into Cancer and Nutrition (EPIC) cohorts from 10 European countries. Public Health Nutr 5 , 1179-1196.

48. Vidavalur R, Otani H, Singal PK, et al. (2006) Significance of wine and resveratrol in cardiovascular disease: French paradox revisited. Exp Clin Cardiol 11, 217-225.

49. Thorp AA, Healy GN, Owen N, et al. (2010) Deleterious associations of sitting time and television viewing time with cardiometabolic risk biomarkers: Australian Diabetes, Obesity and Lifestyle (AusDiab) study 2004-2005. Diabetes Care 33, 327-334.

50. Jakes RW, Day NE, Khaw KT, et al. (2003) Television viewing and low participation in vigorous recreation are independently associated with obesity and markers of cardiovascular disease risk: EPIC-Norfolk population-based study. Eur J Clin Nutr 57, 1089-1096.

51. McFadden E, Luben R, Wareham N, et al. (2008) Occupational social class, risk factors and cardiovascular disease incidence in men and women: a prospective study in the European Prospective Investigation of Cancer and Nutrition in Norfolk (EPIC-Norfolk) cohort. Eur J Epidemiol 23, 449-458.

52. Johannot L \& Somerset SM (2006) Age-related variations in flavonoid intake and sources in the Australian population. Public Health Nutr 9, 1045-1054.

53. Whichelow MJ, Erzinclioglu SW \& Cox BD (1991) A comparison of the diets of non-smokers and smokers. Br J Addict 86, $71-81$.

54. Dauchet L, Montaye M, Ruidavets JB, et al. (2010) Association between the frequency of fruit and vegetable consumption and cardiovascular disease in male smokers and non-smokers. Eur J Clin Nutr 64, 578-586.

55. Cui Y, Morgenstern H, Greenland S, et al. (2008) Dietary flavonoid intake and lung cancer - a population-based case-control study. Cancer 112, 2241-2248.

56. Bobe G, Weinstein SJ, Albanes D, et al. (2008) Flavonoid intake and risk of pancreatic cancer in male smokers (Finland). Cancer Epidemiol Biomarkers Prev 17, $553-562$.

57. Hughes LA, Arts IC, Ambergen T, et al. (2008) Higher dietary flavone, flavonol, and catechin intakes are associated with less of an increase in BMI over time in women: a longitudinal analysis from the Netherlands Cohort Study. Am J Clin Nutr 88, 1341-1352

58. Hulshof KF, Brussaard JH, Kruizinga AG, et al. (2003) Socio-economic status, dietary intake and $10 \mathrm{y}$ trends: the Dutch National Food Consumption Survey. Eur J Clin Nutr 57, 128-137.

59. Williamson G \& Holst B (2008) Dietary reference intake (DRI) value for dietary polyphenols: are we heading in the right direction? Br J Nutr 99, Suppl. 3, S55-S58.

60. Otaki N, Kimira M, Katsumata S, et al. (2009) Distribution and major sources of flavonoid intakes in the middle-aged Japanese women. J Clin Biochem Nutr 44, 231-238.

61. Dilis V \& Trichopoulou A (2010) Antioxidant intakes and food sources in Greek adults. J Nutr 140, 1274-1279.

62. Beking K \& Vieira A (2011) An assessment of dietary flavonoid intake in the UK and Ireland. Int J Food Sci Nutr 62, $17-19$.

63. Arts IC, Hollman PC, Feskens EJ, et al. (2001) Catechin intake might explain the inverse relation between tea consumption and ischemic heart disease: the Zutphen Elderly Study. Am J Clin Nutr 74, 227-232.

64. Kyle JA, Sharp L, Little J, et al. (2010) Dietary flavonoid intake and colorectal cancer: a case-control study. Br J Nutr 103, 429-436.

65. Perez-Jimenez J, Fezeu L, Touvier M, et al. (2011) Dietary intake of 337 polyphenols in French adults. Am J Clin Nutr 93, $1220-1228$

66. Ovaskainen ML, Torronen R, Koponen JM, et al. (2008) Dietary intake and major food sources of polyphenols in Finnish adults. $J$ Nutr 138, 562-566.

67. Wang Y, Chung SJ, Song WO, et al. (2011) Estimation of daily proanthocyanidin intake and major food sources in the U.S. diet. J Nutr 141, 447-452.

68. Skeie G, Braaten T, Hjartaker A, et al. (2009) Use of dietary supplements in the European Prospective Investigation into Cancer and Nutrition calibration study. Eur J Clin Nutr 63, Suppl. 4, S226-S238. 
Annex 1. Adjusted ${ }^{\star}$ mean daily intakes $(\mathrm{mg} / \mathrm{d})$ of flavan-3-ol monomer compounds by European Prospective Investigation into Cancer and Nutrition centre ordered from south to north

(Mean values with their standard errors)

\begin{tabular}{|c|c|c|c|c|c|c|c|c|c|c|c|c|c|c|c|}
\hline \multirow[b]{3}{*}{ Country and centre } & \multicolumn{15}{|c|}{ Flavan-3-ol monomers } \\
\hline & \multirow[b]{2}{*}{$n$} & \multicolumn{2}{|c|}{$(+)$-Catechin } & \multicolumn{2}{|c|}{$\begin{array}{l}(-) \text {-Epicate- } \\
\text { chin }\end{array}$} & \multicolumn{2}{|c|}{$\begin{array}{l}(-) \text {-Epigallo- } \\
\text { catechin }\end{array}$} & \multicolumn{2}{|c|}{$\begin{array}{l}(-) \text {-Epicate- } \\
\text { chin 3-gallate }\end{array}$} & \multicolumn{2}{|c|}{$\begin{array}{l}\text { (-)-Epigallo- } \\
\text { catechin } \\
\text { 3-gallate }\end{array}$} & \multicolumn{2}{|c|}{$\begin{array}{l}(+) \text {-Galloca- } \\
\text { techin }\end{array}$} & \multicolumn{2}{|c|}{$\begin{array}{c}(+) \text {-Catechin } \\
\text { 3-gallate }\end{array}$} \\
\hline & & Mean & SE & Mean & SE & Mean & SE & Mean & SE & Mean & SE & Mean & SE & Mean & SE \\
\hline $\begin{array}{l}\text { Greece } \\
\text { Spain }\end{array}$ & 2687 & $8 \cdot 21$ & 0.27 & $9 \cdot 63$ & 0.31 & $1 \cdot 26$ & 0.37 & 1.40 & 0.31 & 1.58 & 0.92 & 0.50 & 0.08 & 1.07 & 0.28 \\
\hline \multicolumn{16}{|l|}{ Spain } \\
\hline Murcia & 547 & $15 \cdot 67$ & 0.61 & $12 \cdot 59$ & 0.68 & $\begin{array}{l}1.05 \\
1.92\end{array}$ & 0.82 & 1.86 & 0.69 & $1 \cdot 18$ & 2.05 & 0.33 & 0.17 & 0.40 & 0.61 \\
\hline Navarra & 715 & 14.46 & 0.54 & $12 \cdot 50$ & 0.61 & 1.67 & 0.73 & 0.79 & 0.62 & 0.88 & 1.83 & 0.16 & 0.15 & 0.15 & 0.55 \\
\hline San Sebastian & 734 & 17.69 & 0.55 & $16 \cdot 60$ & 0.62 & $2 \cdot 35$ & 0.75 & 1.26 & 0.63 & 1.41 & 1.87 & 0.24 & 0.16 & 0.33 & 0.56 \\
\hline Asturias & 710 & $17 \cdot 85$ & 0.53 & $19 \cdot 25$ & 0.59 & $2 \cdot 64$ & 0.72 & 1.48 & 0.60 & $2 \cdot 35$ & 1.79 & 0.21 & 0.15 & 0.33 & 0.54 \\
\hline \multicolumn{16}{|l|}{ Italy } \\
\hline Ragusa & 306 & $15 \cdot 04$ & 0.81 & $14 \cdot 74$ & 0.91 & $4 \cdot 28$ & 1.09 & $2 \cdot 47$ & 0.92 & 8.09 & 2.73 & 0.44 & 0.23 & 0.55 & 0.82 \\
\hline Naples & 403 & $10 \cdot 34$ & 0.70 & 11.46 & 0.79 & 3.64 & 0.95 & 2.45 & 0.80 & 8.05 & 2.37 & 0.40 & 0.20 & 0.56 & 0.71 \\
\hline Florence & 1055 & $16 \cdot 43$ & 0.50 & $17 \cdot 22$ & 0.56 & $5 \cdot 81$ & 0.67 & 3.92 & 0.56 & $12 \cdot 54$ & 1.67 & 0.79 & 0.14 & 1.09 & 0.50 \\
\hline Turin & 1068 & 21.84 & 0.45 & $20 \cdot 31$ & 0.50 & 6.44 & 0.60 & $4 \cdot 61$ & 0.51 & 14.57 & 1.51 & 0.93 & 0.13 & $1 \cdot 38$ & 0.45 \\
\hline Varese & 1121 & $18 \cdot 87$ & 0.46 & $18 \cdot 36$ & 0.52 & 7.67 & 0.62 & $6 \cdot 10$ & 0.53 & 19.86 & 1.56 & 1.13 & 0.13 & $1 \cdot 80$ & 0.47 \\
\hline \multicolumn{16}{|l|}{ France } \\
\hline South coast & 620 & 14.53 & 0.56 & $17 \cdot 26$ & 0.63 & 7.63 & 0.76 & $7 \cdot 19$ & 0.64 & $10 \cdot 71$ & 1.91 & 1.84 & 0.16 & 6.96 & 0.57 \\
\hline South & 1425 & $15 \cdot 41$ & 0.37 & $18 \cdot 37$ & 0.42 & 11.01 & 0.50 & $9 \cdot 79$ & 0.42 & 14.63 & 1.26 & 2.76 & 0.11 & $10 \cdot 62$ & 0.38 \\
\hline North-East & 2059 & $15 \cdot 80$ & 0.31 & 18.44 & 0.35 & $10 \cdot 07$ & 0.42 & $8 \cdot 86$ & 0.35 & 13.62 & 1.05 & $2 \cdot 45$ & 0.09 & $9 \cdot 32$ & 0.31 \\
\hline North-West & 631 & 14.83 & 0.56 & 17.54 & 0.63 & 11.68 & 0.76 & $9 \cdot 85$ & 0.64 & $15 \cdot 31$ & 1.89 & 2.99 & 0.16 & 11.49 & 0.57 \\
\hline \multicolumn{16}{|l|}{ Germany } \\
\hline Heidelberg & 2121 & 18.94 & 0.31 & $20 \cdot 42$ & 0.35 & $13 \cdot 12$ & 0.42 & 13.03 & 0.35 & 22.91 & 1.04 & $2 \cdot 43$ & 0.09 & 7.04 & 0.31 \\
\hline Potsdam & 2294 & $16 \cdot 16$ & 0.29 & $15 \cdot 73$ & 0.33 & $7 \cdot 27$ & 0.40 & 8.76 & 0.34 & 11.45 & 1.00 & 1.63 & 0.08 & 4.98 & 0.30 \\
\hline \multicolumn{16}{|l|}{ The Netherlands } \\
\hline Bilthoven & 2110 & 14.77 & 0.31 & 13.98 & 0.35 & $12 \cdot 32$ & 0.42 & $9 \cdot 77$ & 0.36 & $15 \cdot 22$ & 1.06 & 3.36 & 0.09 & 12.45 & 0.32 \\
\hline Utrecht & 1870 & 14.46 & 0.33 & $16 \cdot 50$ & 0.37 & $19 \cdot 40$ & 0.44 & $15 \cdot 25$ & 0.37 & 23.61 & $1 \cdot 10$ & $5 \cdot 18$ & 0.09 & $20 \cdot 24$ & 0.33 \\
\hline \multicolumn{16}{|l|}{ UK } \\
\hline General & 974 & $22 \cdot 76$ & 0.46 & 23.91 & 0.51 & 35.07 & 0.62 & $26 \cdot 44$ & 0.52 & $42 \cdot 61$ & 1.55 & $9 \cdot 30$ & 0.13 & 35.96 & 0.46 \\
\hline Health-conscious & 309 & $19 \cdot 87$ & 0.83 & $20 \cdot 06$ & 0.93 & $26 \cdot 18$ & $1 \cdot 12$ & 21.93 & 0.94 & 31.08 & $2 \cdot 81$ & 6.82 & 0.24 & $26 \cdot 53$ & 0.84 \\
\hline \multicolumn{16}{|l|}{ Denmark } \\
\hline Copenhagen & 2840 & $23 \cdot 27$ & 0.26 & 19.09 & 0.30 & $12 \cdot 92$ & 0.36 & $10 \cdot 65$ & 0.30 & $16 \cdot 46$ & 0.89 & 3.69 & 0.08 & 12.93 & 0.27 \\
\hline Aarhus & 1077 & $21 \cdot 85$ & 0.43 & $20 \cdot 99$ & 0.48 & $10 \cdot 50$ & 0.58 & 8.98 & 0.49 & $13 \cdot 87$ & 1.45 & $2 \cdot 92$ & 0.12 & $10 \cdot 01$ & 0.44 \\
\hline \multicolumn{16}{|l|}{ Sweden } \\
\hline Malmö & 3132 & $12 \cdot 27$ & 0.26 & $13 \cdot 83$ & 0.29 & $14 \cdot 30$ & 0.35 & $12 \cdot 01$ & 0.30 & 43.44 & 0.88 & $2 \cdot 10$ & 0.07 & 3.42 & 0.27 \\
\hline Umeå & 2918 & $11 \cdot 15$ & 0.26 & 14.09 & 0.29 & $16 \cdot 33$ & 0.35 & 13.63 & 0.30 & 49.99 & 0.88 & 2.35 & 0.07 & 3.89 & 0.27 \\
\hline \multicolumn{16}{|l|}{ Norway } \\
\hline South and East & 1004 & 13.39 & 0.45 & $15 \cdot 81$ & 0.50 & $12 \cdot 17$ & 0.61 & $10 \cdot 70$ & 0.51 & 22.04 & 1.52 & 2.57 & 0.13 & 8.48 & 0.45 \\
\hline North and West & 793 & $11 \cdot 70$ & 0.50 & 14.68 & 0.57 & $9 \cdot 46$ & 0.68 & 8.93 & 0.57 & $17 \cdot 75$ & 1.70 & 1.88 & 0.14 & 6.09 & 0.51 \\
\hline
\end{tabular}

*Adjusted for sex and age, and weighted by season and day of recall. 
Annex 2. Adjusted* mean daily intakes (mg/d) of proanthocyanidin (PA) and theaflavin subgroups by European Prospective Investigation into Cancer and Nutrition centre ordered from south to north (Mean values with their standard errors)

\begin{tabular}{|c|c|c|c|c|c|c|c|c|c|c|c|c|c|c|c|c|c|c|c|}
\hline \multirow[b]{3}{*}{ Country and centre } & \multirow[b]{3}{*}{$n$} & \multicolumn{10}{|c|}{ PA } & \multicolumn{8}{|c|}{ Theaflavins } \\
\hline & & \multicolumn{2}{|c|}{$\begin{array}{c}\text { PA } \\
\text { dimers }\end{array}$} & \multicolumn{2}{|c|}{$\begin{array}{c}\text { PA } \\
\text { trimers }\end{array}$} & \multicolumn{2}{|c|}{$\begin{array}{c}\text { PA } \\
4-6 \text { mers }\end{array}$} & \multicolumn{2}{|c|}{$\begin{array}{c}\text { PA } \\
7-10 \text { mers }\end{array}$} & \multicolumn{2}{|c|}{$\begin{array}{c}\text { PA } \\
>10 \text { mers }\end{array}$} & \multicolumn{2}{|c|}{ Theaflavin } & \multicolumn{2}{|c|}{$\begin{array}{l}\text { Theaflavin- } \\
3,3^{\prime} \text {-digallate }\end{array}$} & \multicolumn{2}{|c|}{$\begin{array}{l}\text { Theaflavin- } \\
3^{\prime} \text {-gallate }\end{array}$} & \multicolumn{2}{|c|}{$\begin{array}{l}\text { Theaflavin- } \\
\text { 3-gallate }\end{array}$} \\
\hline & & Mean & SE & Mean & SE & Mean & SE & Mean & SE & Mean & SE & Mean & SE & Mean & SE & Mean & SE & Mean & $\mathrm{SE}$ \\
\hline Granada & 514 & 36.4 & 1.8 & $12 \cdot 7$ & 0.7 & 41.9 & $2 \cdot 1$ & 30.0 & 1.6 & 63.1 & 5.4 & 0.07 & 0.13 & 0.06 & 0.11 & 0.06 & 0.11 & 0.06 & 0.11 \\
\hline Murcia & 547 & 38.7 & 1.7 & $14 \cdot 2$ & 0.7 & $46 \cdot 9$ & $2 \cdot 0$ & $33 \cdot 2$ & 1.5 & $64 \cdot 8$ & $5 \cdot 2$ & 0.06 & 0.13 & 0.05 & 0.11 & 0.05 & 0.11 & 0.05 & 0.11 \\
\hline Navarra & 715 & 39.1 & 1.5 & 13.1 & 0.6 & $45 \cdot 9$ & 1.8 & $34 \cdot 1$ & 1.4 & 70.4 & 4.6 & 0.01 & 0.11 & 0.01 & 0.10 & 0.01 & $0 \cdot 10$ & 0.01 & 0.10 \\
\hline San Sebastian & 734 & $56 \cdot 1$ & 1.6 & $20 \cdot 3$ & 0.6 & $69 \cdot 8$ & $1 \cdot 8$ & $53 \cdot 3$ & 1.4 & $105 \cdot 7$ & 4.7 & 0.06 & 0.11 & 0.05 & $0 \cdot 10$ & 0.05 & $0 \cdot 10$ & 0.05 & 0.10 \\
\hline Asturias & 710 & $61 \cdot 7$ & 1.5 & $25 \cdot 7$ & 0.6 & 83.0 & 1.8 & $63 \cdot 0$ & 1.3 & 114.6 & 4.5 & 0.05 & 0.11 & 0.04 & 0.10 & 0.04 & 0.10 & 0.04 & 0.09 \\
\hline \multicolumn{20}{|l|}{ Italy } \\
\hline Ragusa & 306 & $44 \cdot 3$ & $2 \cdot 3$ & $15 \cdot 5$ & 0.9 & $52 \cdot 6$ & $2 \cdot 7$ & $38 \cdot 3$ & $2 \cdot 1$ & $79 \cdot 6$ & 6.9 & 0.13 & 0.17 & 0.11 & 0.15 & 0.11 & 0.15 & 0.11 & 0.14 \\
\hline Naples & 403 & 31.1 & $2 \cdot 0$ & $13 \cdot 3$ & 0.8 & 43.5 & $2 \cdot 3$ & 30.6 & 1.8 & 61.5 & $6 \cdot 0$ & 0.14 & 0.15 & 0.12 & 0.13 & 0.12 & 0.13 & 0.11 & 0.13 \\
\hline Florence & 1055 & 50.1 & 1.4 & 18.5 & 0.6 & 60.9 & 1.6 & 44.7 & 1.3 & $90 \cdot 6$ & 4.2 & 0.22 & 0.10 & 0.19 & 0.09 & 0.19 & 0.09 & 0.19 & 0.09 \\
\hline Turin & 1068 & 61.7 & 1.3 & 19.9 & 0.5 & $67 \cdot 3$ & 1.5 & 49.5 & 1.1 & 100.1 & 3.8 & 0.26 & 0.09 & 0.22 & 0.08 & 0.22 & 0.08 & 0.21 & 0.08 \\
\hline Varese & 1121 & 53.4 & 1.3 & $17 \cdot 0$ & 0.5 & $56 \cdot 0$ & 1.5 & 41.4 & 1.2 & $85 \cdot 1$ & 3.9 & 0.37 & $0 \cdot 10$ & 0.32 & 0.08 & 0.32 & 0.08 & 0.31 & 0.08 \\
\hline \multicolumn{20}{|l|}{ France } \\
\hline South coast & 620 & $36 \cdot 7$ & 1.6 & $12 \cdot 2$ & 0.6 & $40 \cdot 1$ & 1.9 & 28.0 & 1.4 & $62 \cdot 8$ & 4.8 & 1.40 & 0.12 & 1.23 & 0.10 & 1.23 & 0.10 & 1.20 & 0.10 \\
\hline South & 1425 & 40.8 & $1 \cdot 1$ & 13.9 & 0.4 & $44 \cdot 1$ & 1.2 & 31.3 & 0.9 & $69 \cdot 6$ & $3 \cdot 2$ & $2 \cdot 14$ & 0.08 & 1.88 & 0.07 & 1.88 & 0.07 & 1.84 & 0.07 \\
\hline North-East & 2059 & 41.9 & 0.9 & 14.8 & 0.4 & $46 \cdot 2$ & 1.0 & $32 \cdot 0$ & 0.8 & 69.5 & $2 \cdot 6$ & 1.88 & 0.06 & 1.64 & 0.06 & 1.64 & 0.06 & 1.61 & 0.06 \\
\hline North-West & 631 & 40.5 & 1.6 & 13.6 & 0.6 & $42 \cdot 8$ & 1.9 & 30.8 & 1.4 & 61.0 & 4.8 & $2 \cdot 31$ & 0.12 & 2.03 & 0.10 & 2.03 & $0 \cdot 10$ & 1.99 & 0.10 \\
\hline \multicolumn{20}{|l|}{ Germany } \\
\hline Heidelberg & 2121 & $45 \cdot 5$ & 0.9 & $17 \cdot 2$ & 0.4 & 43.9 & 1.0 & 32.4 & 0.8 & 69.4 & $2 \cdot 6$ & 1.39 & 0.06 & 1.20 & 0.06 & 1.20 & 0.06 & $1 \cdot 19$ & 0.06 \\
\hline Potsdam & 2294 & 33.1 & 0.8 & 14.9 & 0.3 & 44.4 & 1.0 & $32 \cdot 8$ & 0.8 & 74.5 & 2.5 & 0.92 & 0.06 & 0.80 & 0.05 & 0.80 & 0.05 & 0.79 & 0.05 \\
\hline \multicolumn{20}{|l|}{ The Netherlands } \\
\hline Bilthoven & 2110 & 29.6 & 0.9 & $10 \cdot 6$ & 0.4 & 29.9 & 1.0 & 21.0 & 0.8 & 44.4 & $2 \cdot 7$ & 2.52 & 0.07 & $2 \cdot 20$ & 0.06 & $2 \cdot 20$ & 0.06 & $2 \cdot 16$ & 0.06 \\
\hline Utrecht & 1870 & $36 \cdot 1$ & 0.9 & $12 \cdot 1$ & 0.4 & 33.7 & $1 \cdot 1$ & $24 \cdot 3$ & 0.8 & $50 \cdot 1$ & $2 \cdot 8$ & $4 \cdot 10$ & 0.07 & 3.59 & 0.06 & 3.59 & 0.06 & 3.52 & 0.06 \\
\hline \multicolumn{20}{|l|}{ UK } \\
\hline General population & 974 & 58.5 & 1.3 & 14.8 & 0.5 & 34.3 & 1.5 & 23.9 & 1.2 & $52 \cdot 7$ & 3.9 & $7 \cdot 32$ & $0 \cdot 10$ & $6 \cdot 41$ & 0.08 & 6.41 & 0.08 & 6.29 & 0.08 \\
\hline Health-conscious & 309 & 51.9 & $2 \cdot 3$ & 18.0 & 1.0 & $46 \cdot 8$ & $2 \cdot 8$ & $36 \cdot 1$ & $2 \cdot 1$ & $85 \cdot 2$ & $7 \cdot 1$ & $5 \cdot 37$ & 0.17 & $4 \cdot 70$ & 0.15 & 4.70 & 0.15 & 4.62 & 0.15 \\
\hline \multicolumn{20}{|l|}{ Denmark } \\
\hline Copenhagen & 2840 & 58.9 & 0.7 & $15 \cdot 1$ & 0.3 & 43.5 & 0.9 & 30.4 & 0.7 & 65.5 & $2 \cdot 3$ & $2 \cdot 62$ & 0.05 & $2 \cdot 30$ & 0.05 & $2 \cdot 30$ & 0.05 & $2 \cdot 25$ & 0.05 \\
\hline Aarhus & 1077 & 57.9 & $1 \cdot 2$ & $17 \cdot 7$ & 0.5 & $51 \cdot 7$ & 1.4 & $36 \cdot 6$ & 1.1 & $69 \cdot 3$ & 3.7 & 2.02 & 0.09 & 1.77 & 0.08 & 1.77 & 0.08 & 1.74 & 0.08 \\
\hline Sweden & & & & & & & & & & & & & & & & & & & \\
\hline Malmö & 3132 & $26 \cdot 3$ & 0.7 & $10 \cdot 1$ & 0.3 & $28 \cdot 2$ & 0.9 & $19 \cdot 4$ & 0.7 & $50 \cdot 3$ & $2 \cdot 2$ & 0.83 & 0.05 & 0.72 & 0.05 & 0.72 & 0.05 & 0.69 & 0.05 \\
\hline Umeå & 2918 & 23.4 & 0.7 & $10 \cdot 3$ & 0.3 & $28 \cdot 2$ & 0.9 & 21.8 & 0.7 & $80 \cdot 7$ & $2 \cdot 2$ & 0.95 & 0.05 & 0.82 & 0.05 & 0.82 & 0.05 & 0.79 & 0.05 \\
\hline Norway & & & & & & & & & & & & & & & & & & & \\
\hline South and East & 1004 & $32 \cdot 2$ & 1.3 & $12 \cdot 0$ & 0.5 & $35 \cdot 6$ & 1.5 & 28.5 & $1 \cdot 1$ & $98 \cdot 8$ & 3.8 & 1.73 & 0.09 & 1.50 & 0.08 & 1.50 & 0.08 & 1.48 & 0.08 \\
\hline North and West & 793 & 31.1 & 1.4 & $12 \cdot 6$ & 0.6 & $37 \cdot 1$ & 1.7 & 29.5 & 1.3 & $103 \cdot 7$ & 4.3 & 1.23 & $0 \cdot 10$ & 1.07 & 0.09 & 1.07 & 0.09 & 1.06 & 0.09 \\
\hline
\end{tabular}

*Adjusted for sex and age, and weighted by season and day of recall. 